\title{
Aggregate Comovements, Anticipation, and Business Cycles
}

\author{
David R.F. Love ${ }^{1}$
}

Department of Economics, Brock University

June 2007

\begin{abstract}
This paper points out that negative comovements between macroeconomic aggregates are commonly observed in US data and that this is not explained by conventional business cycle models which emphasize positive comovements only. We discuss how these facts can be readily explained in simple Neoclassical models by the dynamic responses to signals (news) about future economic fundamentals unrelated to current fundamentals. These "anticipation effects" are contrasted with the effects of immediate shocks to current fundamentals which are the main source of fluctuations in standard RBC models. Simulation results illustrate that the enriched model dynamics under the anticipation assumption can replicate both the positive and negative comovements observed in the data and magnifies the effects of shocks, without negative implications for the model's predictions regarding other moments.
\end{abstract}

Keywords: Comovements, Anticipation, News, Real Business Cycles, Equilibrium Dynamics.

JEL: E10, E30, E37.

\footnotetext{
${ }^{1}$ Correspondence to David Love, Department of Economics, Brock University, St. Catharines, Ont. CAN. L2S 3A1. email: loved@brocku.ca.
} 


\section{Introduction.}

The prototypical business-cycle model emphasizes positive comovements between major macroeconomic aggregates. After all, this is the stylized view of the business cycle. Yet, growth rates of U.S. quarterly real per-capita consumption $(C)$, capital investment $\left(I_{K}\right)$, output $(Y)$, and hours worked $(H)$ are far from perfectly correlated (see Table 1).

Table 1. Contemporaneous Correlations.

Growth Rates, Qtly Obs. 1953(I)-2006(II).

\begin{tabular}{|c||c|c|c|c|}
\hline & $C$ & $I_{K}$ & $Y$ & $H$ \\
\hline \hline$C$ & 1.0 & 0.398 & 0.585 & 0.208 \\
\hline$I_{K}$ & & 1.0 & 0.743 & 0.397 \\
\hline$Y$ & & & 1.0 & 0.422 \\
\hline$H$ & & & & 1.0 \\
\hline
\end{tabular}

A low correlation may not mean negative comovements, but it turns out that for the 215 quarterly observations on these growth-rates between 1953(I) and 2006(II), less than one-quarter (50) involved all four rates changing in the same direction. Alternatively, for about $75 \%$ of the observations at least one rate was falling while the others were increasing, or vice-versa.

Hodrick-Prescott (HP) filtered data, the standard benchmark for evaluating Real Business Cycle (RBC) models, are by construction more highly correlated than first-differenced data (Cogley and Nason, 1995, Canova, 1998). So HP-filtered data better conforms with business-cycle models that are dominated by positive comovements. Yet at least a third of these observations also involve negative comovements.

Table 2. Contemporaneous Correlations

HP-Filtered, Qtly Obs. 1953(I)-2006(II).

\begin{tabular}{|c||c|c|c|c|}
\hline & $C$ & $I_{K}$ & $Y$ & $H$ \\
\hline \hline$C$ & 1.0 & 0.794 & 0.859 & 0.636 \\
\hline$I_{K}$ & & 1.0 & 0.925 & 0.747 \\
\hline$Y$ & & & 1.0 & 0.726 \\
\hline$H$ & & & & 1.0 \\
\hline
\end{tabular}


This paper documents the extent of these observed negative comovements in US data, including periods immediately surrounding NBER business-cycle dates, and shows how they are consistent with "anticipation effects" in simple Neoclassical models. By "anticipation effects" we mean the dynamic responses of an economy to signals, or "news", about future economic fundamentals unrelated to current fundamentals. It is intuitive that information regarding changes in future fundamentals such as new technologies, government budgets, and regulations is often available and that it can influence the current decisions of forward looking rational agents. Beaudry and Portier (2006) provide recent evidence on the quantitative significance of this showing that as much as $50 \%$ of business-cycle fluctuations may be explained by such "news shocks".

The fact that simple Neoclassical models deliver negative comovements in response to anticipated changes is well known but has been seen as problematic in light of the stylized view of business cycles. One approach, as in the RBC literature, assumes that information innovations arise only from realizations of stochastic "shocks" to current fundamentals. These shocks then are the only source of forecast innovations driving the model's dynamics, and these unanticipated changes in current fundamentals imply positive comovements almost exclusively.

Alternatively, under an anticipation assumption, information innovations stem from other sources such as news about recent scientific discoveries. Forecasts can anticipate changes in future fundamentals not predicted by current fundamentals and forward looking agents will respond accordingly. If an anticipated change in fundamentals is not realized on the date expected, this is analogous to an unanticipated change in current fundamentals. For example, not realizing an anticipated $1 \%$ increase in TFP means agents are less wealthy than expected and yields qualitatively identical dynamics to realizing a $1 \%$ decline when no change was expected. So, allowing for anticipation in forming forecasts opens the possibility of explaining economic downturns in simple RBC models without appealing to technological regress.

Beaudry and Portier (2004a, 2004b), and Jaimovich and Rebelo (2006), pursue these ideas with some success in developing models of "expectations driven business cycles". To maintain the anticipation effects required here without the negative comovements predicted in Neoclassical frameworks, they study modified models characterized by positive comovements only as consistent with the stylized view of business cycles.

This paper is complementary to the above work in maintaining the view that "news shocks" are an important source of macroeconomic fluctuations. However, on examining data comovements closely in relation to model results we find little evidence for the rejection of anticipation effects in the Neoclassical framework on the basis of its prediction of negative comovements. In fact, models that narrowly predict only positive comovements appear far more at odds with the data.

Another finding under scoring these conclusions is that the predominance of positive comovements in HP-filtered data is far more an artifact of the spurious smoothing operation of this filter than a reflection of 
the true empirical characteristics the data.

Taking the view that anticipation effects in standard RBC models are not empirically implausible, we examine the effects of reliable signals about future fundamentals on these models under simulation. We find that assuming anticipation vastly improves the model's predictions for patterns of comovements in the data. In addition, there is an increased magnification of shocks in the model, and mixed effects on predictions for the relative volatilities and cross-correlations central to the RBC literature.

Section 2 below briefly illustrates theoretical transitional dynamics from the basic model, and highlights the implications for comovements under the alternative assumptions of anticipated changes versus immediate shocks to productivity. Section 3 then presents evidence on these comovements from our sample of U.S. data. Section 4 presents simulation results on these comovements from the model. Section 5 illustrates implications of the anticipation assumption for other moments. Section 6 concludes.

\section{Theoretical Growth Rate Dynamics}

The theoretical benchmark employed in this paper is a simple one-sector Neoclassical growth model common to the early RBC literature (eg. Prescott, 1986, Christiano and Eichenbaum, 1992). There is a single representative household which maximizes expected utility according to,

$$
U=E_{0}\left\{\sum_{t=0}^{\infty} \beta^{t} u\left(C_{t},\left(1-l_{t}\right)\right)\right\} .
$$

$C_{t}$ is period-t consumption, and $l_{t}$ is labour supplied from a unit endowment of time per period. $\beta<1$ is the household's subjective rate of time preference. The period utility function over consumption and leisure is parameterized as:

$$
u\left(C_{t}, 1-l_{t}\right)=\ln \left(C_{t}\right)+\gamma V\left(1-l_{t}\right), \quad \gamma>0,
$$

where $V(\bullet)$ is specified as, $\ln \left(1-l_{t}\right)$ under the divisible-labour assumption, or as $\left(1-l_{t}\right)$ under the indivisiblelabour assumption (Hansen, 1985).

The household's labour supply earns a competitive wage rate, $w_{t}$. Households also save directly in capital which is rented out each period for a competitive rate of return $r_{t}$, and which follows the usual law of motion, $K_{t+1}=(1-\delta) K_{t}+I_{K t}$, where $\delta \in(0,1)$ gives the rate of capital depreciation. The resulting household income is allocated between consumption goods and capital investments implying the following time-t budget constraint, 


$$
C_{t} \leq w_{t} l_{t}+r_{t} K_{t}-I_{K t}
$$

The production of output, $Y_{t}$, is undertaken by a representative firm which employs labour and rents capital to maximize period-by-period profits with a constant returns to scale production technology,

$$
Y_{t}=A S_{t} K_{t}^{\alpha} l_{t}^{1-\alpha}
$$

Where, $A>0$, and $\alpha \in(0,1)$ are standard production function coefficients. $S_{t}>0$ is an exogenous total-factor productivity (TFP) variable or "technology shock" assumed to follow a random walk with drift,

$$
\ln \left(S_{t}\right)=\ln \left(S_{t-1}\right)+\mu+\xi_{S t}, \quad \xi_{S t} \sim \text { i.i.d. } N\left(0, \sigma_{S}^{2}\right)
$$

The drift parameter $\mu$, determines the long-run rate of growth of the economy and hence the balanced-growth path (BGP) equilibrium characterized by stationary per-capita hours and difference-stationary per-capita output, consumption, and capital stocks.

Capital adjustment costs, variable capacity utilization, and other refinements do not generally alter the equilibrium dynamics of interest here (Beaudry and Portier 2004, 2005 and Jaimovich and Rebelo, 2006) and will not change our basic conclusions.

Figure 1 illustrates these well-known dynamics for this class of models. Growth-rate deviations from the BGP (normalized by standard deviations) are plotted over time. The economy is assumed to be on its BGP in period zero. At the start of period 1 reliable information arrives anticipating an upcoming $1 \%$ increase in TFP effective at the start of period 4 . The growth rate of consumption rises relative to its BGP value while the growth rates of investment, hours, and output fall. Subsequently, each growth rate returns towards its BGP value until the TFP improvement is realized in period 4. The responses to this realization, specifically the positive comovements between all variables, are qualitatively identical to those stemming from a fully unanticipated TFP improvement.

In this example then there is an "anticipation effect" with two periods ( 0 to 1 , and 1 to 2 ) of negative comovement between consumption and the other variables, plus a "realized productivity effect" with two periods ( 3 to 4 , and 4 to 5 ) of positive comovement between all of the variables. Both effects stem from a single anticipated change in TFP. In contrast, a single unanticipated change in TFP would result in only the positive comovements.

Anticipation spreads the economy's response to the shock out over time by allowing for a separation of income and substitution effects. The income effect occurs first with anticipated higher future output 
Figure 1: Model Growth Rates with Anticipated Productivity Improvement. Growth rate deviations from BGP normalized by standard deviations.

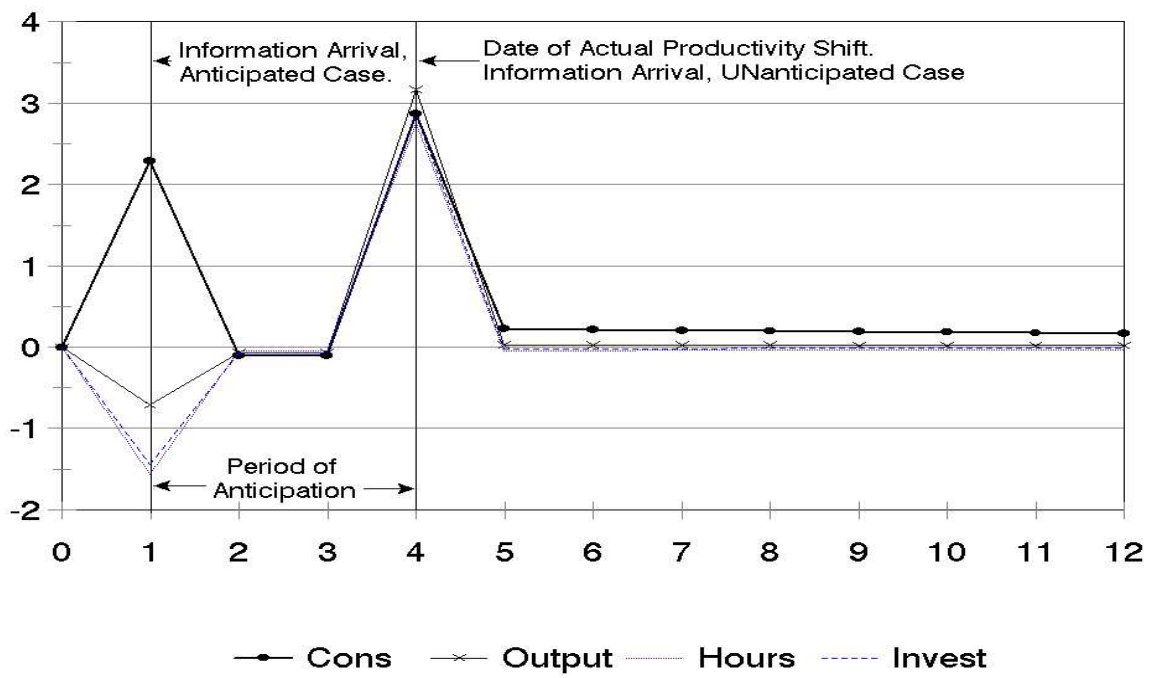

causing consumption and leisure to rise. Since hours fall and capital is fixed at the time of the "news shock," investment must fall to facilitate increased consumption. The substitution effect, increasing hours, occurs with the realized TFP improvement when higher output allows more investment and consumption simultaneously. As discussed by Beaudry and Portier (2004) a high intertemporal elasticity of substitution (IES) in the model (i.e. $\gg 1$ ) can lead to an inversion of these growth rate dynamics. In any case, the anticipation effect continues to result in negative comovements between consumption growth and growth of the other variables.

For the purposes of the remainder of the paper we need a systematic way of categorizing these different equilibrium dynamic responses. Consider initially the responses of consumption growth $\left(g_{C}\right)$ and investment growth $\left(g_{I_{K}}\right)$ only ${ }^{1}$. Grouping these into periods of either positive or negative growth results in four possible combinations or "cases" which may be conveniently represented in the following table.

\begin{tabular}{l|c|c|} 
& \multicolumn{1}{c}{$g_{C}^{-}$} & \multicolumn{1}{c}{$g_{C}^{+}$} \\
\cline { 2 - 3 }$g_{I_{K}}^{-}$ & $\mathrm{I}$ & $\mathrm{III}$ \\
\cline { 2 - 3 }$g_{I_{K}}^{+}$ & $\mathrm{II}$ & $\mathrm{IV}$ \\
\cline { 2 - 3 } & &
\end{tabular}

Heuristically speaking for the moment, if we assume purely unanticipated shocks to TFP, the model's equilibrium dynamics would yield purely positive comovements of consumption and investment growth due to

\footnotetext{
${ }^{1}$ Beaudry and Portier (2004) show that consumption and investment always vary inversely in response to anticipated productivity or demand shifts in this framework.
} 
realized productivity effects. That is, cases I or IV only should be observed. Alternatively, under anticipated changes as in figure 1 cases II and/or III should be observed. But the assumption of anticipated changes is also consistent with observed positive comovements (I and IV) due to the predicted dynamics upon the realization of a given change (or lack thereof). On the other hand, the model under the assumption of purely unanticipated shocks or other models with equilibrium dynamics that predict only positive comovements, are inconsistent with observations of cases II or III.

Thus, under the maintained assumption of this model, the number and pattern of cells observed in this nonparametric methodology are informative about the underlying shock process.

It is also important to note that, for a number of reasons, the signs of growth-rate deviations from BGP may be relatively poor indicators of the frequency of anticipation effects. In Figure 1 for example, period-1 would show opposite signs for $g_{C}$ and $g_{I_{K}}$, periods- 2 and 3 would show both negative, period- 4 both positive, and then opposite signs would be observed again during the transition back to the BGP. This would tend to overestimate the frequency of anticipation effects. On the other hand, if shocks arrive continuously, as is typically assumed in the RBC literature, overlapping responses can obscure the observations in different ways. For example, downwards pressure on investment growth-rates due to anticipation effects may compete with upwards pressure in the same period stemming from contemporaneous realizations of previously anticipated TFP improvements. In such instances, cases II or III would only be observed when the anticipation effects are relatively large. Alternatively, if a news shock arrives during a transition period when growth rates are say, above their BGP values, then the downwards pressure on one of the rates due to the anticipation effect may not be sufficient to push it below its BGP value into negative territory leading to an underestimation of the frequency of anticipation effects.

In theory, however, the direction of change of growth rates would continue to reveal the presence of anticipation effects despite these problems. Thus, observing the slopes of growth-rate paths may enable a more accurate estimation of the presence and frequency of anticipation effects in the data, to which we turn in the next section of this paper.

\section{Empirical Evidence.}

Our data sample is comprised of 215 quarterly observations on real per-capita seasonally adjusted data from the U.S. economy for the period 1953:1 to 2006:2. Details of data sources and compilation are provided in Appendix A and our data files are available for download from, http://spartan.ac.brocku.ca/ loved/data. 


\subsection{Measures of Comovement.}

We construct four measures from our data to relate to the dynamic responses discussed in section 2 above. The first are the deviations of variable growth rates from their sample mean denoted as $(1-L) x_{t}-\bar{\mu}$. This is the sample analogue to the BGP deviations illustrated in figure 1. The second, denoted $H P_{t}$, are simply the detrended growth rate series obtained from an HP-filter with smoothing parameter equal to 1600 .

The other two alternatives for identifying anticipation effects are first-differences of the above growthrate measures. These are denoted as $(1-L)^{2} x_{t}$ and $(1-L) H P_{t}$ respectively ${ }^{2}$. As mentioned in Section 2, growth-rate signs may not accurately identify anticipation effects when, in theory, observations on the slopes of growth-rate paths will. First-differencing also eliminates the sensitivity to estimated means of the $(1-L) x_{t}-\bar{\mu}$ measure. More importantly though, for integrated or near unit-root series, the HP-filter is known to spuriously generate business cycle comovement which can mask differences between sample and theoretical dynamics (Cogley and Nason, 1995). Here the smoothing operation of the HP-filter, moving growth rates onto the same side of the stochastic trend, could eliminate sign differences necessary to identify anticipation effects according to the model. Intuitively, however, the signs of growth-rate changes may survive the shifting of growth-rate levels.

Table 1 provides means and standard errors of these alternative measures (last four rows) of the dynamic properties of real per-capita consumption $(C)$, investment $\left(I_{K}\right)$, output $(Y)$, and hours $(H)$ from our data sample, in addition to the levels and growth rates of each of these variables.

Table 1: Summary Statistics

\begin{tabular}{|c||c|c|c|c|c|c|c|c|}
\hline Variables $\rightarrow$ & \multicolumn{2}{|c|}{ Cons. $(C)$} & \multicolumn{2}{c|}{ Invest. $\left(I_{K}\right)$} & \multicolumn{2}{c|}{ Output $(Y)$} & \multicolumn{2}{c|}{ Hours $(H)$} \\
\hline Filters $\downarrow$ & mean & s.e. & mean & s.e. & mean & s.e. & mean & s.e. \\
\hline \hline Level $\left(x_{t}\right)$ & 19.56 & 5.42 & 7.51 & 3.17 & 33.31 & 9.12 & 0.191 & 0.005 \\
\hline$(1-L) x_{t}$ & 0.0047 & 0.0047 & 0.0065 & 0.021 & 0.0044 & 0.008 & -0.0003 & 0.011 \\
\hline \hline$(1-L) x_{t}-\bar{\mu}$ & 0.0 & 0.0047 & 0.0 & 0.021 & 0.0 & 0.008 & 0.0 & 0.011 \\
\hline$H P_{t}$ & 0.0 & 0.008 & 0.0 & 0.038 & 0.0 & 0.014 & 0.0 & 0.015 \\
\hline$(1-L)^{2} x_{t}$ & $-2.0 \mathrm{e}-5$ & 0.006 & $-4.0 \mathrm{e}-5$ & 0.024 & $-3.0 \mathrm{e}-5$ & 0.009 & $1.0 \mathrm{e}-5$ & 0.015 \\
\hline$(1-L) H P_{t}$ & $-3.0 \mathrm{e}-5$ & 0.004 & $-1.0 \mathrm{e}-5$ & 0.019 & $-7.0 \mathrm{e}-5$ & 0.007 & $-7.0 \mathrm{e}-5$ & 0.011 \\
\hline
\end{tabular}

\subsection{Consumption and Investment Comovements.}

Continuing our focus on consumption and investment, table 2 presents the observed frequencies from our data sample of the four possible sign combinations under each of our four measures. Episodes of positive

\footnotetext{
${ }^{2}$ These measures are dated: $y_{t-1}^{d g}=(1-L)^{2} x_{t}, y_{t-1}^{d h p}=(1-L) H P_{t}$.
} 
comovement in the sample are generally more numerous. However, episodes of negative comovement make up between $19 \%$ and $49 \%$ of the sample depending on which measure is observed.

Table 2: Patterns of Comovement, $C$ and $I_{K}$.

\begin{tabular}{|c|c|c|c|c|c|}
\hline \multicolumn{3}{|c|}{$(1-L) x_{t}-\bar{\mu}$} & \multicolumn{3}{|c|}{$H P_{t}$} \\
\hline \multirow{4}{*}{$\begin{array}{l}I_{K}^{-} \\
I_{K}^{+}\end{array}$} & $\overline{C^{-}}$ & $\mathrm{C}^{+}$ & \multirow{4}{*}{$\begin{array}{l}I_{K}^{-} \\
I_{K}^{+}\end{array}$} & \multicolumn{2}{|l|}{$\bar{C}^{-}$} \\
\hline & $61(29 \%)$ & $43(20 \%)$ & & $82(38 \%)$ & $19(9 \%)$ \\
\hline & $44(21 \%)$ & $66(31 \%)$ & & $22(10 \%)$ & $92(43 \%)$ \\
\hline & \multicolumn{2}{|c|}{$\begin{array}{c}\chi^{2}=7.44(1 \text { d.f. }) \\
(\mathrm{P}=0.006)\end{array}$} & & \multicolumn{2}{|c|}{$\begin{array}{c}\chi^{2}=82.1(1 \text { d.f. }) \\
(\mathrm{P}=0.0)\end{array}$} \\
\hline \multicolumn{3}{|c|}{$(1-L)^{2} x_{t}$} & \multicolumn{3}{|c|}{$(1-L) H P_{t}$} \\
\hline \multirow{3}{*}{$\begin{array}{l}I_{K}^{-} \\
I_{K}^{+}\end{array}$} & $\overline{C^{-}}$ & $\bar{C}^{+}$ & \multirow{4}{*}{$\begin{array}{l}I_{K}^{-} \\
I_{K}^{+}\end{array}$} & \multicolumn{2}{|l|}{$\mathrm{C}^{-}$} \\
\hline & $54(25 \%)$ & $49(23 \%)$ & & $66(31 \%)$ & $41(19 \%)$ \\
\hline & $55(26 \%)$ & $55(26 \%)$ & & $39(18 \%)$ & $68(32 \%)$ \\
\hline \multicolumn{3}{|c|}{$\begin{array}{c}\chi^{2}=0.125(1 \text { d.f. }) \\
(P=0.723)\end{array}$} & & \multicolumn{2}{|c|}{$\begin{array}{c}\chi^{2}=13.6(1 \text { d.f. }) \\
(\mathrm{P}=0.0002)\end{array}$} \\
\hline
\end{tabular}

Employing the row and column totals from each table it is straightforward to calculate the Chi-square statistic reported at the bottom of each panel for the null hypothesis of no association between the variables ${ }^{3}$. In all but the $(1-L)^{2} x_{t}$-case "no association" is strongly rejected. This implies a statistically significant underlying structure influencing these observations. The distinct predominance of positive comovements in the $H P_{t}$-case, however, suggests that this implied structure may simply be the HP-filter itself. Similarly, on an observation-by-observation basis, the $H P_{t}$-measure generally yields very different categorizations of variable comovements from the other 3 measures. Of the 213 observations after taking lags, only 9 result in the same categorization from all four measures. However, this jumps to 89 consistent categorizations when the $H P_{t}$-measure is excluded. Considering groups of two, the $(1-L) x_{t}-\bar{\mu}$ and $(1-L)^{2} x_{t}$-measures yield 99 consistent categorizations, the $(1-L) x_{t}-\bar{\mu}$ and $(1-L) H P_{t}$-measures yield 159 , and the $(1-L)^{2} x_{t}$ and $(1-L) H P_{t^{-}}$-measures yield $121^{4}$.

In any case there is ample evidence of the presence of negative comovements between consumption and investment which, as we have seen, may be explained by anticipation effects in the simple Neoclassical framework. The evidence does not support the rejection of the joint assumption of a Neoclassical model and anticipated changes on the basis of the fact that it implies negative comovements. On the other hand, it is clearly inconsistent with the model under purely unanticipated shocks or with alternative frameworks that

\footnotetext{
${ }^{3} \chi^{2}=\sum_{i, j}\left(N_{i j}-n_{i j}\right)^{2} / n_{i j}$, where $N_{i j}$ is the number of observations, and $n_{i j}$ is the expected number calculated under the null hypothesis from only the row and column totals, for the $i^{\text {th }}$ row and $j^{\text {th }}$ column.

${ }^{4}$ Similarly disparate predictions of different data filters for business cycle facts are documented by Canova (1998).
} 
predict only positive comovements between these variables. This is not to argue that the model at hand is an adequate representation of the business cycle, but only that these features of the data beg an explanation, and that anticipation in the Neoclassical framework may provide a ready one.

\subsection{Relation to Business Cycle Dates.}

It is natural to ask if these observed categorizations of comovements can be related to any other recognizable features of the business cycle. Appendix B contains the category numbers from the scheme outlined in above obtained for observations bracketing each of the nine NBER dated business cycle peaks and troughs in our sample.

A first impression from studying these tables again relates to the disparities in the sample across the alternative measures of comovement. As expected, the $H P_{t}$-measure is generally more uniform than the other 3 measures and produces a far greater proportion of positive comovements over the cycle. Nonetheless, periods of negative comovements are about as prevalent around peaks and troughs $(17 \%$ to $50 \%$ of observations) as for the entire sample and are certainly not absent.

The emphasis on positive comovements in the prototypical business cycle model implies that business cycle peaks should be characterized by movements from positive or increasing growth rates to negative or decreasing rates. That is, we should observe sequences like IV $\rightarrow \mathrm{I}$ at or near peak dates. For the 4 measures across 9 peaks in our sample only 7 from a maximum of 36 such sequences are observed within one quarter on either side of peak dates. The opposite dynamic $\mathrm{I} \rightarrow \mathrm{IV}$, is expected at or near troughs. Only 3 such observations arise within one quarter on either side of trough dates.

Considering a less demanding test, the $H P_{t}$-measure shows 7 of 9 peaks characterized by positive growth rates of both variables (IV's) and 8 of 9 troughs by negative growth rates (I's). Furthermore, the $(1-L) H P_{t^{-}}$ measure shows 8 peaks characterized by declining growth rates for both variables (I's), and 5 troughs characterized by rising growth rates (IV's) at the NBER dates. These observations conform with the prototypical model view. However, the smoothing effects of the HP-filter already discussed raises some suspicion. Smoothing effects may also explain the long 4-quarter average of post-trough decline observed in the $H P_{t}$-measures. Simulation results presented in Section 4 below confirm these suspicions.

Observations on the $(1-L) x_{t}-\bar{\mu}$ and $(1-L)^{2} x_{t}$-measures around NBER business-cycle dates are less uniform. The $(1-L)^{2} x_{t}$-measure shows declining growth rates for both variables (I's) at 5 peak dates, and increasing rates for both variables (IV's) at 4 trough dates (another 4 occur one-quarter before the trough dates). This is roughly in accordance with the prototypical model predictions and the $(1-L) H P_{t}$-measure. However, the $(1-L) x_{t}-\bar{\mu}$ measure shows below average growth for both variables (I's) at all 9 dated peaks, 
and no consistent characterization for the troughs.

Finally, there is a notable pattern of negative comovements in these data at or immediately following troughs. The $(1-L) x_{t}-\bar{\mu}$-measure shows below average consumption growth and above average investment growth (II's) at or one-quarter after 5 of the 9 trough dates; 1958:2, 1961:1, 1970:4, 1975:1, 1980:3. The $(1-L) H P_{t}$ and $(1-L)^{2} x_{t}$-measures show declining consumption growth and increasing investment growth (also II's) at or one-quarter after 6 and 7 trough dates respectively ${ }^{5}$. These investment-lead recoveries are consistent with a number of alternative scenarios in the Neoclassical model. For example, they may reflect the second-half of the anticipation effect illustrated in Figure 1 for a productivity improvement. A third of these observations are proceeded by the opposite dynamics (III's) consistent with the first-half of the anticipation effect in this example. There are also several observations consistent with anticipation effects nearing peaks (eg. 1960:2, 1969:4, and 1990:3), but no obvious patterns emerge. Keep in mind that overlapping responses from contemporaneous productivity shifts (I's and IV's) can hide the presence of anticipation effects (II's and III's). Whatever the case, while there may be many plausible explanations for the negative comovements observed, models which predict only positive comovements are not amongst them.

\subsection{Four-Variable Comovements.}

Two-variable correlations and tables as discussed so far offer only a limited test of the model which predicts the simultaneous negative comovement of consumption with investment, output, and hours, in anticipation of fundamental changes. By appropriate grouping of possible sign combinations multiple-variable comovements can be analyzed with the same categorization methods as above in the two-variable cases.

Table 3 illustrates one categorization (denoted with lower case Roman numerals) of the 16 possible sign combinations describing the joint movements of consumption, investment, output, and hours.

\section{Table 3: Four-Variable Categorizations}

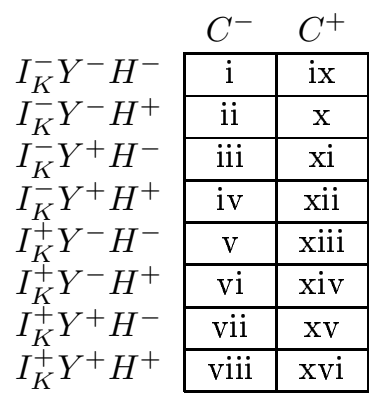

As before, consumption changes are treated as one variable with the two possible outcomes (signs)

\footnotetext{
${ }^{5} 1991: 1$ is the additional trough date for $(1-L) H P_{t}$. For $(1-L) x_{t}$ we also observe this date plus 1954:2, and 2001:4, but not 1980:3.
} 
represented by the columns of the table. The rows of the table categorize a composite second variable which has eight possible outcomes (sign combinations) depending on the joint behaviour of changes of investment, output and hours. Thus the table exhausts the categories of possible outcomes without redundancies and the row and column totals are informative about changes in consumption vis-a-vis the joint behaviour of investment, output, and hours.

Table 4 presents the observed frequencies of these 16 possibilities from our data sample. The Chi-square statistic reported at the bottom of each panel provides a test for the null hypothesis of no association between changes in consumption and combinations of changes in the other three variables.

Table 4: Four-Variable Patterns of Comovement.

\begin{tabular}{|c|c|c|c|c|c|}
\hline \multicolumn{3}{|c|}{$(1-L) x_{t}-\bar{\mu}$} & \multicolumn{3}{|c|}{$H P_{t}$} \\
\hline \multirow{9}{*}{$\begin{array}{l}I_{K}^{-} Y^{-} H^{-} \\
I_{K}^{-} Y^{-} H^{+} \\
I_{K}^{-} Y^{+} H^{-} \\
I_{K}^{-} Y^{+} H^{+} \\
I_{K}^{+} Y^{-} H^{-} \\
I_{K}^{+} Y^{-} H^{+} \\
I_{K}^{+} Y^{+} H^{-} \\
I_{K}^{+} Y^{+} H^{+}\end{array}$} & \multicolumn{2}{|r|}{$C^{+}$} & \multirow{9}{*}{$\begin{array}{l}I_{K}^{-} Y^{-} H^{-} \\
I_{K}^{-} Y^{-} H^{+} \\
I_{K}^{-} Y^{+} H^{-} \\
I_{K}^{-} Y^{+} H^{+} \\
I_{K}^{+} Y^{-} H^{-} \\
I_{K}^{+} Y^{-} H^{+} \\
I_{K}^{+} Y^{+} H^{-} \\
I_{K}^{+} Y^{+} H^{+}\end{array}$} & \multicolumn{2}{|r|}{$C^{+}$} \\
\hline & $34(16 \%)$ & $16(7 \%)$ & & $65(30 \%)$ & $9(4 \%)$ \\
\hline & $21(10 \%)$ & $10(5 \%)$ & & $9(4 \%)$ & $2(1 \%)$ \\
\hline & $3(1 \%)$ & $6(3 \%)$ & & $4(2 \%)$ & $5(2 \%)$ \\
\hline & $3(1 \%)$ & $11(5 \%)$ & & $4(2 \%)$ & $3(1 \%)$ \\
\hline & $7(3 \%)$ & $3(1 \%)$ & & $6(3 \%)$ & $0(0 \%)$ \\
\hline & $11(5 \%)$ & $6(3 \%)$ & & $5(2 \%)$ & $2(1 \%)$ \\
\hline & $5(2 \%)$ & $19(9 \%)$ & & $3(1 \%)$ & $9(4 \%)$ \\
\hline & $21(10 \%)$ & $38(18 \%)$ & & $8(4 \%)$ & $81(38 \%)$ \\
\hline \multicolumn{3}{|c|}{$\begin{array}{c}\chi^{2}=32.0(7 \text { d.f. }) \\
(P=0.0)\end{array}$} & \multicolumn{3}{|c|}{$\begin{array}{c}\chi^{2}=117.2(7 \text { d.f. }) \\
(P=0.0)\end{array}$} \\
\hline
\end{tabular}

\begin{tabular}{|c|c|c|c|c|c|}
\hline \multicolumn{3}{|c|}{$(1-L)^{2} x_{t}$} & \multicolumn{3}{|c|}{$(1-L) H P_{t}$} \\
\hline \multirow{9}{*}{$\begin{array}{c}I_{K}^{-} Y^{-} H^{-} \\
I_{K}^{-} Y^{-} H^{+} \\
I_{K}^{-} Y^{+} H^{-} \\
I_{K}^{-} Y^{+} H^{+} \\
I_{K}^{+} Y^{-} H^{-} \\
I_{K}^{+} Y^{-} H^{+} \\
I_{K}^{+} Y^{+} H^{-} \\
I_{K}^{+} Y^{+} H^{+}\end{array}$} & \multicolumn{2}{|l|}{$C^{-}$} & \multirow{9}{*}{$\begin{array}{l}I_{K}^{-} Y^{-} H^{-} \\
I_{K}^{-} Y^{-} H^{+} \\
I_{K}^{-} Y^{+} H^{-} \\
I_{K}^{-} Y^{+} H^{+} \\
I_{K}^{+} Y^{-} H^{-} \\
I_{K}^{+} Y^{-} H^{+} \\
I_{K}^{+} Y^{+} H^{-} \\
I_{K}^{+} Y^{+} H^{+}\end{array}$} & \multicolumn{2}{|r|}{$\bar{C}^{+}$} \\
\hline & $28(13 \%)$ & $16(8 \%)$ & & $36(17 \%)$ & $15(7 \%)$ \\
\hline & $14(7 \%)$ & $11(5 \%)$ & & $18(8 \%)$ & $12(6 \%)$ \\
\hline & $5(2 \%)$ & $14(7 \%)$ & & $2(1 \%)$ & $6(3 \%)$ \\
\hline & $7(3 \%)$ & $8(4 \%)$ & & $10(5 \%)$ & $8(4 \%)$ \\
\hline & $11(5 \%)$ & $8(4 \%)$ & & $4(2 \%)$ & $8(4 \%)$ \\
\hline & $9(4 \%)$ & $9(4 \%)$ & & $10(5 \%)$ & $7(3 \%)$ \\
\hline & $19(9 \%)$ & $14(7 \%)$ & & $6(3 \%)$ & $20(9 \%)$ \\
\hline & $16(8 \%)$ & $24(11 \%)$ & & $19(9 \%)$ & $33(15 \%)$ \\
\hline \multicolumn{3}{|c|}{$\begin{array}{c}\chi^{2}=10.68(7 \text { d.f. }) \\
(P=0.153)\end{array}$} & \multicolumn{3}{|c|}{$\begin{array}{c}\chi^{2}=25.2(7 \text { d.f. }) \\
(P=0.0007)\end{array}$} \\
\hline
\end{tabular}

Positive comovements between all four variables (cells $\mathrm{i}$ and $\mathrm{xvi}$ ) are the most common observations ranging from $24 \%$ to $68 \%$ of the sample. The $H P_{t}$-measure again appears anomalous, with at least twice as many such observations as the other three measures, and no other sign-combination individually yielding more than $4 \%$ of the sample. For the other three measures negative comovements comprise the majority of the sample. Regardless of the measure observed, however, two categories of negative comovements consistently 
stand out as the second most frequently observed outcomes. The first of these, accounting for between $8 \%$ and $17 \%$ of the sample, are when consumption moves inversely with investment, output, and hours (cells viii and ix). As in Figure 1, these types of comovements are predicted by the Neoclassical model under anticipated productivity changes. The second prevalent category of negative comovements, accounting for between $8 \%$ and $19 \%$ of the sample, are when hours move inversely with consumption, investment, and output (cells ii and xv). As we shall see in Section 4 below, these are also predicted by the Neoclassical model, but for "demand shocks".

As expected, increasing the number of variables from two to four reduces the consistency of categorizations obtained from the four different measures. For the $H P_{t}$-measure only 5 of 215 observations yield the same categorization across all four different measures. This jumps to 41 consistent categorizations when the $H P_{t^{-}}$-measure is excluded. There are 54 consistent categorizations between the $(1-L) x_{t}-\bar{\mu}$ and $(1-L)^{2} x_{t^{-}}$ measures, 130 between the $(1-L) x_{t}-\bar{\mu}$ and $(1-L) H P_{t}$-measures and 63 between the $(1-L)^{2} x_{t}$ and $(1-L) H P_{t}$-measures.

Regarding negative comovements and NBER business cycle dates, increasing the number of variables from 2 to 4 necessarily increases the number of types of negative comovements and, given the results of Section 3.3 above, it is not surprising to observe a variety of these showing up in and around business cycle peaks and troughs. Yet it turns out that eleven of the 18 observations at or immediately following NBER trough dates where consumption growth was low and/or falling while investment growth was high and/or rising also exhibit the high and/or rising output and hours associated with anticipation effects in the Neoclassical model. Alternatively, excluding the anomalous $H P_{t}$-measure, at least a third of the troughs in our sample exhibit behaviour that is inconsistent with business cycle models emphasizing only positive comovements between these aggregates.

\section{Model Simulations.}

In this section we use the simulation methodology of the RBC literature (Kydland and Prescott (1982), Prescott(1986)) to evaluate the ability of basic Neoclassical models to replicate the empirical evidence on comovements discussed above. Simulations will also prove useful in establishing the reliability of the different measures of comovement for identifying the presence of anticipation effects and for estimating their frequency in the data. The focus here is limited to the model of Section 2, and some straightforward variations on it.

Love, D. and J.F. Lamarche (2004) details the simulation methodology for anticipated changes and documents the robustness of anticipation effects in a larger set of RBC models. We employ the deterministic extended path method due to Fair and Taylor (1984). Gagnon (1990) and Taylor and Uhlig (1990) discuss 
this method in solving non-linear stochastic growth models and find a high degree of accuracy relative to grid methods. Love (2007) finds an order of magnitude reduction in Euler-equation errors with this method relative to the projection methods of Judd (1992).

\subsection{The Benchmark Case.}

We take as our "benchmark" case the divisible-labour model of Section 2 under the assumption of purely unanticipated shocks to TFP. As usual time periods are assumed to correspond to quarterly observations. For comparability with other literature we employ the calibration of Christiano and Eichenbaum (1992) with the exception that we set the innovation variance to match the variance of per capita GDP growth (0.008) from our data sample. Note that in this model the intertemporal elasticity of substitution (IES) is unity. Table 5 provides a summary of the parameter settings and corresponding balanced-growth variable values for this benchmark calibration.

Table 5: Parameters and Balanced-Growth Variables: Base-Case Calibration.

\begin{tabular}{|c|}
\hline Model Parameters \\
\hline$A=1.0, \alpha=0.344, \delta=0.021$ \\
\hline$\beta=0.9926, \gamma=2.99, I E S=1.0$ \\
\hline$\mu=0.0026, \sigma_{S}=0.00621$ \\
\hline Balanced-Growth Variable Values \\
\hline$g=0.004, l=0.23, \sigma_{g_{Y}}=0.008$ \\
\hline Kinv $/ Y=0.265, r-\delta=0.0114$ \\
\hline
\end{tabular}

Table 6 presents the average frequencies in percentages of the 16 possible four-variable comovements predicted by the benchmark model from 1000 simulated time-series of 215 observations. The model generally fails to yield any significant percentages of negative comovements between variables. Chi-square statistics for the test of association cannot even be calculated due to singularities in these sparse tables reflecting the narrow structure of the model. Similarly, cells with zero frequency imply an immediate rejection of the model on the basis of Chi-square goodness-of-fit measures relative to the data. The non-zero frequencies of negative comovements observed in the data cannot be explained by a model that puts zero probability on such outcomes.

For the $H P_{t}$ and $(1-L) x_{t}-\bar{\mu}$-measures, cells viii and ix (negative comovements) account for about $5 \%$ of observations, even though these simulations involved no anticipated shocks at all! These observations, and the other negative comovements categorized by these two measures, are explained by the model 's dynamics as it returns to its BGP subsequent to a realized TFP shock. In the case of a positive shock for example, 
Table 6: Benchmark Model Simulations

\begin{tabular}{|c|c|c|c|c|c|}
\hline \multicolumn{3}{|c|}{$(1-L) x_{t}-\bar{\mu}$} & \multicolumn{3}{|c|}{$H P_{t}$} \\
\hline \multirow{9}{*}{$\begin{array}{c}I_{K}^{-} Y^{-} H^{-} \\
I_{K}^{-} Y^{-} H^{+} \\
I_{K}^{-} Y^{+} H^{-} \\
I_{K}^{-} Y^{+} H^{+} \\
I_{K}^{+} Y^{-} H^{-} \\
I_{K}^{+} Y^{-} H^{+} \\
I_{K}^{+} Y^{+} H^{-} \\
I_{K}^{+} Y^{+} H^{+}\end{array}$} & $C^{-}$ & $\overline{C^{+}}$ & \multirow{9}{*}{$\begin{array}{c}I_{K}^{-} Y^{-} H^{-} \\
I_{K}^{-} Y^{-} H^{+} \\
I_{K}^{-} Y^{+} H^{-} \\
I_{K}^{-} Y^{+} H^{+} \\
I_{K}^{+} Y^{-} H^{-} \\
I_{K}^{+} Y^{-} H^{+} \\
I_{K}^{+} Y^{+} H^{-} \\
I_{K}^{+} Y^{+} H^{+}\end{array}$} & $C^{-}$ & $\bar{C}^{+}$ \\
\hline & $45.1 \%$ & $2.2 \%$ & & $44.1 \%$ & $2.7 \%$ \\
\hline & $1.1 \%$ & $0 \%$ & & $1.3 \%$ & $0 \%$ \\
\hline & $0 \%$ & $1.5 \%$ & & $0 \%$ & $1.6 \%$ \\
\hline & $0 \%$ & $0 \%$ & & $0 \%$ & $0 \%$ \\
\hline & $0 \%$ & $0 \%$ & & $0 \%$ & $0 \%$ \\
\hline & $1.5 \%$ & $0 \%$ & & $1.9 \%$ & $0 \%$ \\
\hline & $0 \%$ & $1.2 \%$ & & $0 \%$ & $1.5 \%$ \\
\hline & $2.3 \%$ & $45.1 \%$ & & $2.8 \%$ & $44.0 \%$ \\
\hline
\end{tabular}

\begin{tabular}{|c|c|c|c|c|c|}
\hline \multicolumn{3}{|c|}{$(1-L)^{2} x_{t}$} & \multicolumn{3}{|c|}{$(1-L) H P_{t}$} \\
\hline \multirow{9}{*}{$\begin{array}{l}I_{K}^{-} Y^{-} H^{-} \\
I_{K}^{-} Y^{-} H^{+} \\
I_{K}^{-} Y^{+} H^{-} \\
I_{K}^{-} Y^{+} H^{+} \\
I_{K}^{+} Y^{-} H^{-} \\
I_{K}^{+} Y^{-} H^{+} \\
I_{K}^{+} Y^{+} H^{-} \\
I_{K}^{+} Y^{+} H^{+}\end{array}$} & $C^{-}$ & $C^{+}$ & \multirow{9}{*}{$\begin{array}{c}I_{K}^{-} Y^{-} H^{-} \\
I_{K}^{-} Y^{-} H^{+} \\
I_{K}^{-} Y^{+} H^{-} \\
I_{K}^{-} Y^{+} H^{+} \\
I_{K}^{+} Y^{-} H^{-} \\
I_{K}^{+} Y^{-} H^{+} \\
I_{K}^{+} Y^{+} H^{-} \\
I_{K}^{+} Y^{+} H^{+}\end{array}$} & \multicolumn{2}{|c|}{$C^{-} \quad C^{+}$} \\
\hline & $49.1 \%$ & $0.4 \%$ & & $47.8 \%$ & $1 \%$ \\
\hline & $0.2 \%$ & $0 \%$ & & $0.5 \%$ & $0 \%$ \\
\hline & $0 \%$ & $0.3 \%$ & & $0 \%$ & $0.6 \%$ \\
\hline & $0 \%$ & $0 \%$ & & $0 \%$ & $0 \%$ \\
\hline & $0 \%$ & $0 \%$ & & $0 \%$ & $0 \%$ \\
\hline & $0.2 \%$ & $0 \%$ & & $0.7 \%$ & $0 \%$ \\
\hline & $0 \%$ & $0.1 \%$ & & $0 \%$ & $0.5 \%$ \\
\hline & $0.4 \%$ & $49.2 \%$ & & $1 \%$ & $47.8 \%$ \\
\hline
\end{tabular}

during this phase of the transition consumption and output growth tend to remain above their BGP values while growth of investment and hours linger below.

This illustrates the difficulties discussed in Section 2 regarding the use of categorizations of growthrate deviations for the identification and estimation of the frequency of anticipation effects. As expected, however, the first-differences of growth rates are more reliable. In particular, the $(1-L)^{2} x_{t^{-}}$measure shows less than $2 \%$ deviation on average from the perfect positive correlation which theoretically define this model's dynamics. The $(1-L) H P_{t}$-measure is less accurate than that, perhaps due to the smoothing operation of the HP-filter, but significantly improves over both of the growth-rate deviation measures. This offers some confidence for our interpretation of the empirical evidence presented in Section 3.

Regarding the consistency of categorizations across the four measures, in general the results are much more homogeneous for this simulated data. However, the $H P_{t^{-}}$measure continues to stand apart from the other 3 measures. On average 55 of 213 observations after taking lags yield the same categorization across all four different measures. This jumps to 142 consistent categorizations on average when the $H P_{t}$-measure is excluded, 147 on average between the $(1-L) x_{t}-\bar{\mu}$ and $(1-L)^{2} x_{t}$-measures, 185 between the $(1-L) x_{t}-\bar{\mu}$ and $(1-L) H P_{t}$-measures, and 156 between the $(1-L)^{2} x_{t}$ and $(1-L) H P_{t}$-measures. This is qualitatively 
the same pattern of consistency obtained when looking at the data in Section 3 and is also robust across all of our simulation experiments.

\subsection{Anticipated TFP Changes.}

We now simulate the model under the assumption that upcoming TFP changes are reliably signalled threeperiods before the changes take effect as is in the example of Figure $1^{6}$. Table 7 contains the results of categorizing the comovements from this simulation.

Table 7: Anticipated Changes Model Simulations

\begin{tabular}{|c|c|c|c|c|c|}
\hline \multicolumn{3}{|c|}{$(1-L) x_{t}-\bar{\mu}$} & \multicolumn{3}{|c|}{$H P_{t}$} \\
\hline \multirow{9}{*}{$\begin{array}{c}I_{K}^{-} Y^{-} H^{-} \\
I_{K}^{-} Y^{-} H^{+} \\
I_{K}^{-} Y^{+} H^{-} \\
I_{K}^{-} Y^{+} H^{+} \\
I_{K}^{+} Y^{-} H^{-} \\
I_{K}^{+} Y^{-} H^{+} \\
I_{K}^{+} Y^{+} H^{-} \\
I_{K}^{+} Y^{+} H^{+}\end{array}$} & \multicolumn{2}{|c|}{$C^{-} \quad C^{+}$} & \multirow{9}{*}{$\begin{array}{l}I_{K}^{-} Y^{-} H^{-} \\
I_{K}^{-} Y^{-} H^{+} \\
I_{K}^{-} Y^{+} H^{-} \\
I_{K}^{-} Y^{+} H^{+} \\
I_{K}^{+} Y^{-} H^{-} \\
I_{K}^{+} Y^{-} H^{+} \\
I_{K}^{+} Y^{+} H^{-} \\
I_{K}^{+} Y^{+} H^{+}\end{array}$} & \multicolumn{2}{|c|}{$\begin{array}{ll}C^{-} & C^{+} \\
\end{array}$} \\
\hline & $18.0 \%$ & $28.0 \%$ & & $21.8 \%$ & $23.8 \%$ \\
\hline & $1.0 \%$ & $0 \%$ & & $0.8 \%$ & $0 \%$ \\
\hline & $0 \%$ & $3.1 \%$ & & $0 \%$ & $2.8 \%$ \\
\hline & $0 \%$ & $0 \%$ & & $0 \%$ & $0 \%$ \\
\hline & $0 \%$ & $0 \%$ & & $0 \%$ & $0 \%$ \\
\hline & $3.1 \%$ & $0 \%$ & & $3.6 \%$ & $0 \%$ \\
\hline & $0 \%$ & $1.0 \%$ & & $0 \%$ & $1.5 \%$ \\
\hline & $27.9 \%$ & $18.0 \%$ & & $23.9 \%$ & $21.9 \%$ \\
\hline
\end{tabular}

\begin{tabular}{|c|c|c|c|c|c|}
\hline \multicolumn{3}{|c|}{$(1-L)^{2} x_{t}$} & \multicolumn{3}{|c|}{$(1-L) H P_{t}$} \\
\hline \multicolumn{3}{|c|}{$\begin{array}{ll}C^{-} & C^{+}\end{array}$} & \multicolumn{3}{|c|}{$C^{-}$} \\
\hline \multirow{8}{*}{$\begin{array}{c}I_{K}^{-} Y^{-} H^{-} \\
I_{K}^{-} Y^{-} H^{+} \\
I_{K}^{-} Y^{+} H^{-} \\
I_{K}^{-} Y^{+} H^{+} \\
I_{K}^{+} Y^{-} H^{-} \\
I_{K}^{+} Y^{-} H^{+} \\
I_{K}^{+} Y^{+} H^{-} \\
I_{K}^{+} Y^{+} H^{+}\end{array}$} & $17.8 \%$ & $28.3 \%$ & \multirow{8}{*}{$\begin{array}{l}I_{K}^{-} Y^{-} H^{-} \\
I_{K}^{-} Y^{-} H^{+} \\
I_{K}^{-} Y^{+} H^{-} \\
I_{K}^{-} Y^{+} H^{+} \\
I_{K}^{+} Y^{-} H^{-} \\
I_{K}^{+} Y^{-} H^{+} \\
I_{K}^{+} Y^{+} H^{-} \\
I_{K}^{+} Y^{+} H^{+}\end{array}$} & $17.0 \%$ & $29.3 \%$ \\
\hline & $1.2 \%$ & $0 \%$ & & $0.9 \%$ & $0 \%$ \\
\hline & $0 \%$ & $3.2 \%$ & & $0 \%$ & $2.8 \%$ \\
\hline & $0 \%$ & $0 \%$ & & $0 \%$ & $0 \%$ \\
\hline & $0 \%$ & $0 \%$ & & $0 \%$ & $0 \%$ \\
\hline & $2.8 \%$ & $0 \%$ & & $2.8 \%$ & $0 \%$ \\
\hline & $0 \%$ & $0.8 \%$ & & $0 \%$ & $0.9 \%$ \\
\hline & $28.2 \%$ & $17.6 \%$ & & $29.2 \%$ & $16.9 \%$ \\
\hline
\end{tabular}

The model now predicts both periods of purely positive comovement (cells $\mathrm{i}$ and xvi) and periods of negative comovement between consumption and the other three aggregates (cells viii and ix). As expected, the negative comovements stemming from anticipation effects in some periods are dominated by the positive comovements stemming from contemporary responses to realizations of previously anticipated TFP changes. Thus the assumption of anticipated changes is consistent with both types of observations as observed in the data.

Assuming only anticipated changes does over predict the percentage of observations in cells viii and ix

\footnotetext{
${ }^{6}$ Beaudry and Portier (2004a) estimate anticipation periods of between 2 and 4 quarters using a simulated method of moments.
} 
relative to the data. What is important though is that anticipation improves the model's performance relative to the data by shifting the model away from predicting positive comovements only. Clearly a combination of anticipated and unanticipated changes could modify the proportions of these observations to more closely match the data.

On the other hand, it is also clear from these sparse tables that the model continues to fail to generate the overall diversity of comovements witnessed in the data. This paper is not arguing that the anticipation assumption is a fix for all of the failures of Neoclassical RBC models. The point is that anticipation effects in this model provide a ready explanation for a significant fraction of the observed comovements that are not explained under the standard alternative and thus, ceteris paribus, they offer an improvement in the overall modeling strategy.

Reducing the length of the anticipation period does not change these results qualitatively but, except for the $H P_{t}$-measure, it tends to increase the frequency of observed negative comovements. Notice also the tendency of the $H P_{t}$-measure in Table 7 to smooth away the negative comovements leading it to actually reverse the frequencies of negative and positive comovements observed relative to the other three measures. As a result its consistency with the other three measures in categorizing observations drops dramatically. On average in these simulations only 6 observations out of 213 where placed in the same category by all three measures, but this rises to 100 when the $H P_{t}$-measure is excluded. The spurious effects of the HP-filter on the integrated series simulated here (Cogley and Nason, (1995)), are too large to leave confidence in the use of the $H P_{t}$-measure for the analysis of business cycle comovements. The remainder of the paper drops this misleading $H P_{t}$-measure. We also drop the $(1-L) x_{t}-\bar{\mu}$-measure for further brevity, and because growth-rate deviations are otherwise somewhat unreliable, and since the strong consistency between it and $(1-L) H P_{t}$-measure also implies some redundancy.

\subsection{Government Demand Shocks.}

So-called "demand shocks" are a common additional source of fluctuations in RBC models which can influence their predictions about comovements and may be related to anticipation effects. As in Christiano and Eichenbaum (1995) we now add a simple government sector to the model.

Government expenditure, $G_{t}$, is modeled as a pure resource drain on the economy with no distortional effects. Each period the budget is balanced with a single lump-sum tax, $T_{t}$. Thus $G_{t}=T_{t}$ and the household budget constraint is,

$$
C_{t} \leq w_{t} l_{t}+r_{t} K_{t}-I_{t}-T_{t}
$$


Along a BGP government expenditure is assumed to be a constant proportion of aggregate output, $G_{t}=g Y_{t}$. Otherwise the evolution of government expenditure is modeled as a persistent AR(1) process around the stochastic technology trend implied by Equation 5. That is,

$$
\begin{gathered}
\ln \left(G_{t}\right)=(1-\rho) \bar{G}+\rho \ln \left(G_{t-1}\right)+(1-\rho) \frac{1}{(1-\alpha)} \ln \left(S_{t-1}\right)+\xi_{G t} \\
\xi_{G t} \sim \text { i.i.d. } N\left(0, \sigma_{G}^{2}\right)
\end{gathered}
$$

where

$$
\bar{G}=\ln (g)+\ln \left(Y_{0}\right)-\frac{1}{(1-\alpha)} \ln \left(S_{0}\right) .
$$

The government sector is calibrated as in Christiano and Eichenbaum (1995) with $g=0.177$, and $\rho=0.96$. The relative volatilities of the two shocks is given by $\sigma_{S} / \sigma_{G}(1-\alpha)=0.86$ which, to match the sample variance of per capita GDP growth, requires $\sigma_{S}=0.00576$ and $\sigma_{G}=0.0103$. Lastly we set $\gamma=3.92$ to maintain $l=0.23$, and everywhere else the benchmark calibration is maintained.

For the case of unanticipated changes in government expenditure, the dynamic response of the model is characterized by the standard simultaneous crowding out of both consumption and investment. Alternatively, Figure 2 illustrates the dynamic response of this model to reliable news in period 1 that government expenditure will rise by $1 \%$ in period 4 . The anticipation effect here again involves a negative comovement of consumption with investment, output and hours. Consumption falls at the time of the announcement while hours, output, and investment rise to hedge against the future drain on household budgets. Investment is crowded out only at the time of the actual expenditure increase. This again reflects the separation of income and substitution effects in the model as an optimal response to prior information about future fundamentals.

Table 8 shows the categorization of comovements obtained from simulating the model under the assumption that changes in TFP and government expenditure are purely unanticipated. The addition of demand shocks improves the models predictions for these comovements in three areas without any appeal to anticipation effects.

First, about $5 \%$ of observations now show consumption and investment moving inversely to hours and output (cells iv and xiii). These observations arise from standard crowding out effects of unanticipated demand changes that are large relative to contemporaneous effects of unanticipated TFP changes. Recall that these cells accounted for about $7 \%$ of observations in our data sample.

Second, about $10 \%$ of the simulated observations show hours moving inversely to consumption, investment, and output (cells ii and xv). These dynamics arise in the presence of large unanticipated demand changes simultaneously with relatively small but opposite unanticipated changes in TFP (eg. a $5 \%$ change 
Figure 2: Model Growth Rates with Anticipated Gov't Expenditure Rise. Growth rate deviations from balanced-growth path, normalized by standard deviations.

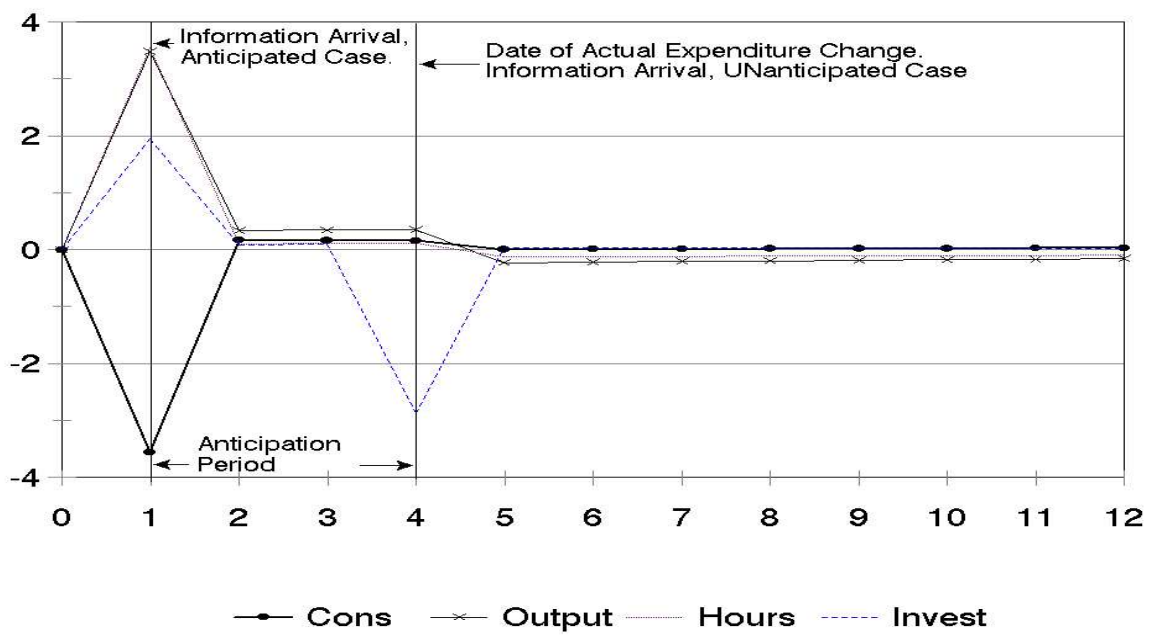

Table 8: Benchmark Model with Government

\begin{tabular}{|c|c|c|c|c|c|}
\hline \multicolumn{3}{|c|}{$(1-L)^{2} x_{t}$} & \multicolumn{3}{|c|}{$(1-L) H P_{t}$} \\
\hline \multirow{9}{*}{$\begin{array}{l}I_{K}^{-} Y^{-} H^{-} \\
I_{K}^{-} Y^{-} H^{+} \\
I_{K}^{-} Y^{+} H^{-} \\
I_{K}^{-} Y^{+} H^{+} \\
I_{K}^{+} Y^{-} H^{-} \\
I_{K}^{+} Y^{-} H^{+} \\
I_{K}^{+} Y^{+} H^{-} \\
I_{K}^{+} Y^{+} H^{+}\end{array}$} & $\overline{\overline{C^{-}}}$ & $\overline{\overline{C^{+}}}$ & \multirow{9}{*}{$\begin{array}{c}I_{K}^{-} Y^{-} H^{-} \\
I_{K}^{-} Y^{-} H^{+} \\
I_{K}^{-} Y^{+} H^{-} \\
I_{K}^{-} Y^{+} H^{+} \\
I_{K}^{+} Y^{-} H^{-} \\
I_{K}^{+} Y^{-} H^{+} \\
I_{K}^{+} Y^{+} H^{-} \\
I_{K}^{+} Y^{+} H^{+}\end{array}$} & $\overline{C^{-}}$ & $C^{+}$ \\
\hline & $38.2 \%$ & $4.2 \%$ & & $37.8 \%$ & $4.4 \%$ \\
\hline & $5.0 \%$ & $0 \%$ & & $5.0 \%$ & $0 \%$ \\
\hline & $0 \%$ & $0 \%$ & & $0 \%$ & $0 \%$ \\
\hline & $2.7 \%$ & $0 \%$ & & $2.6 \%$ & $0 \%$ \\
\hline & $0 \%$ & $2.7 \%$ & & $0.1 \%$ & $2.6 \%$ \\
\hline & $0 \%$ & $0 \%$ & & $0 \%$ & $0 \%$ \\
\hline & $0 \%$ & $5.0 \%$ & & $0 \%$ & $4.9 \%$ \\
\hline & $4.1 \%$ & $38.1 \%$ & & $4.4 \%$ & $37.9 \%$ \\
\hline
\end{tabular}


in $G_{t}$ together with a $-0.5 \%$ change in $S_{t}$ ). These comovements ranked amongst the second most frequently observed in our sample at $14 \%$ for the $(1-L)^{2} x_{t}$-measure, and $17 \%$ for the $(1-L) H P_{t^{-}}$measure.

Third, about $8 \%$ of the simulated observations show consumption moving inversely with investment, output, and hours (cells viii and ix). These we have previously associated with anticipation effects. They are also ranked amongst the second most frequent observations in our sample at $16 \%$ of the $(1-L)^{2} x_{t}$ and $(1-L) H P_{t^{-}}$measures. Here, however, these observations arise when a large unanticipated demand change coincides with a relatively small unanticipated TFP change (eg. a $5 \%$ increase in $G_{t}$ together with a $0.5 \%$ increase in $S_{t}$ ). Thus the addition of demand shocks breaks down the unique identification of this type of comovement with anticipation effects in the model.

On the other hand, the model with unanticipated shocks continues to over predict the frequency of positive comovements at $76 \%$ relative to the data's $24 \%$ to $32 \%$. The sparseness of the simulated frequency tables also continues to reflect the limited nature of the model's dynamics vis-a-vis the data. Adding or substituting other types of shocks to the model is a well studied approach in the RBC literature ${ }^{7}$, which may further address these model limitations and/or account for comovements that we have been identifying with anticipation effects. Intuitively though, the temporal separation of wealth and substitution effects associated with the anticipation of future changes provides a plausible and parsimonious alternative.

\subsection{Anticipated TFP and Government Demand Changes.}

Table 9 shows the categorization of comovements resulting from a model simulation under the assumption that upcoming changes in TFP and government expenditure are reliably signaled 3 periods before they come into effect.

Again, assuming only anticipated changes shifts the model from over predicting purely positive comovements (cells $\mathrm{i}$ and $\mathrm{xvi}$ ) to over predicting negative comovements between consumption and the other three aggregates (cells viii and ix). Observations of the simultaneous crowding out of consumption and investment (cells iv and xiii) are reduced, as are observations of hours moving inversely to the other three aggregates (cells ii and xv). However, anticipation now introduces observations of investment moving inversely to the other three aggregates (cells $\mathrm{v}$ and xii) as illustrated in Figure 2, and about $5 \%$ of observations indicate investment and hours moving inversely to consumption and output (cells vi and xiii). This reduces the singularity in these tables sufficiently to allow for the calculation of the Chi-square statistics reported which, unsurprisingly, reject the null hypothesis of no association. Thus anticipation enriches the dynamics observed in the model without resorting to additional sources of shocks. Strictly speaking of course, the zero cells

\footnotetext{
${ }^{7}$ See for example, Ingram, Kocherlakota, and Savin (1994) on multiple shocks, Baxter and King (1991) for preference shocks, Gomme (1993) for monetary shocks, and Greenwood, Hercowitz and Krusell (2000) for investment-specific technology shocks.
} 
Table 9: Anticipated Changes Model with Government

\begin{tabular}{|c|c|c|c|c|c|}
\hline \multicolumn{3}{|c|}{$(1-L)^{2} x_{t}$} & \multicolumn{3}{|c|}{$(1-L) H P_{t}$} \\
\hline \multicolumn{3}{|c|}{$\overline{\overline{C^{-}}}$} & \multicolumn{3}{|c|}{$C^{-}$} \\
\hline \multirow{8}{*}{$\begin{array}{l}I_{K}^{-} Y^{-} H^{-} \\
I_{K}^{-} Y^{-} H^{+} \\
I_{K}^{-} Y^{+} H^{-} \\
I_{K}^{-} Y^{+} H^{+} \\
I_{K}^{+} Y^{-} H^{-} \\
I_{K}^{+} Y^{-} H^{+} \\
I_{K}^{+} Y^{+} H^{-} \\
I_{K}^{+} Y^{+} H^{+}\end{array}$} & $17.9 \%$ & $27.4 \%$ & \multirow{8}{*}{$\begin{array}{l}I_{K}^{-} Y^{-} H^{-} \\
I_{K}^{-} Y^{-} H^{+} \\
I_{K}^{-} Y^{+} H^{-} \\
I_{K}^{-} Y^{+} H^{+} \\
I_{K}^{+} Y^{-} H^{-} \\
I_{K}^{+} Y^{-} H^{+} \\
I_{K}^{+} Y^{+} H^{-} \\
I_{K}^{+} Y^{+} H^{+}\end{array}$} & $16.5 \%$ & $28.4 \%$ \\
\hline & $1.3 \%$ & $0 \%$ & & $1.2 \%$ & $0 \%$ \\
\hline & $0 \%$ & $2.6 \%$ & & $0 \%$ & $2.4 \%$ \\
\hline & $0.6 \%$ & $1.1 \%$ & & $0.6 \%$ & $1.0 \%$ \\
\hline & $1.0 \%$ & $0.5 \%$ & & $1.0 \%$ & $0.6 \%$ \\
\hline & $2.4 \%$ & $0 \%$ & & $2.4 \%$ & $0 \%$ \\
\hline & $0 \%$ & $1.2 \%$ & & $0 \%$ & $1.1 \%$ \\
\hline & $27.2 \%$ & $17.2 \%$ & & $28.3 \%$ & $16.5 \%$ \\
\hline \multicolumn{3}{|c|}{$\begin{array}{c}\left.\chi^{2}=25.89 \text { (7 d.f. }\right) \\
(P=0.0005)\end{array}$} & \multicolumn{3}{|c|}{$\begin{array}{c}\chi^{2}=28.89(7 \text { d.f. }) \\
(P=0.0002)\end{array}$} \\
\hline
\end{tabular}

remaining continue to imply the rejection of the model on the basis of goodness-of-fit.

\subsection{Robustness.}

Appendix $\mathrm{C}$ presents tables from the simulation of example alternative specifications to our benchmark model with government, along with the calibrated parameter and BGP values for each case. The generalities of the conclusions obtained above are maintained under all of the variations we have examined. However, some sensitivity observed is illustrated here.

The first example employs the indivisible-labour version of the model presented in Section 2. Intuitively, representing utility as linear in leisure allows for a greater flexibility in the dynamic responses of hours. This is apparent in the simulation results assuming unanticipated changes which yield $25 \%$ of observations showing hours moving inversely to the other three aggregates (cells ii and xiii). In comparison, these cells accounted for $10 \%$ of observations in the divisible-labour model and $14 \%-17 \%$ in the data. Under the assumption of anticipated changes, the indivisible versus divisible-labour assumptions make little appreciable difference.

The second and third examples employ alternative intertemporal elasticities of substitution (IES). To allow for this the period utility function is modified as,

$$
u\left(C_{t}, l_{t}\right)=\frac{1}{1-\sigma}\left(C_{t}^{\varepsilon}\left(1-l_{t}\right)^{(1-\varepsilon)}\right)^{(1-\sigma)} \varepsilon \in(0,1), 0 \leq \sigma \neq 1,
$$

which implies $I E S=1 /(1-\varepsilon(1-\sigma))$. Intuitively, a lower IES would inhibit the separation of wealth and substitution effects across time in response to anticipated changes and thus would reduce the prominence of anticipation effects. The opposite should hold in the case of a higher IES.

This shows up in the relative frequencies of purely positive comovements (cells $\mathrm{i}$ and $\mathrm{xvi}$ ) versus the neg- 
ative comovements of consumption with the other three aggregates (cells viii and ix). Under the assumption of anticipated changes only, the high-IES case produces four times as many of these negative comovements as purely positive ones. The low-IES case produces half as many and thus matches the ratio of these observations found in the data without appealing to combinations of anticipated and unanticipated changes. In addition, the frequency of other negative comovements is increased by about $5 \%$ in the low-IES case better matching the data in this regard also. A low-IES is also consistent with the empirical evidence on this elasticity (see for example, Mehra and Prescott (1985)).

\section{Other RBC Stylized Facts and Anticipation}

Given the influence of anticipation on comovements it is natural to ask how this assumption affects the model's predictions about the relative volatilities and correlations central to most RBC analyses. Table 10 presents RBC statistics calculated from our data sample, and from simulations of the low-IES model under alternative assumptions about the period of anticipation; none, 1-quarter, or 3-quarters. Analogous results for the benchmark (IES=1.0) and indivisible-labour models are given in Appendix D. The first panel of the table shows results from $(1-L)$-filtered data, and the second shows results from HP-filtered data.

Anticipation magnifies the effects of shocks in the model. This is seen in the higher variability of output and output growth, and in the higher relative volatility of hours. This magnification means that less reliance on exogenous volatility is required in the model to capture the data, and so addresses an important criticism of RBC theory. Furthermore the result will be inherent to most RBC frameworks as it is due only to the optimal separation over time of wealth and substitution effects in response to anticipated future changes. In the absence of anticipation, agents only learn about changes in fundamentals at the moment they are realized, and wealth effects tend to cancel with substitution effects as they are both compressed into this same time period.

Anticipation also enhances consumption smoothing. This lowers the relative volatility of consumption to output and consumption-output correlations. Consumption smoothing is facilitated by altering investment in anticipation of future changes, and this tends to increase the relative volatility of investment.

Qualitatively, these results apply to all of the parameterizations examined. However, some quantitative sensitivity to alternative parameterizations can be observed (see Appendix D). For example, the correlation between consumption and output-growth actually turns negative for models with IES $=1.0$ or more under the anticipation assumption. Interestingly, a negative correlation between hours and real-wages, as in the data, is predicted by the Indivisible-Labour model under the anticipation assumption. The strong procyclicality of wages in most RBC models is a counterfactual prediction that has proven difficult to address. 
Table 10: Common RBC Statistics: U.S. Data and Benchmark Model

\begin{tabular}{|c|c|c|c|c|}
\hline $\begin{array}{c}(1-L) \text {-Filtered } \\
\text { Data }\end{array}$ & $\begin{array}{c}\text { U.S. } \\
\text { Data }\end{array}$ & $\begin{array}{c}\text { Unanticipated } \\
\text { Benchmark }\end{array}$ & $\begin{array}{c}\text { 1-quarter } \\
\text { Anticipated }\end{array}$ & $\begin{array}{c}\text { 3-quarter } \\
\text { Anticipated }\end{array}$ \\
\hline \hline$\sigma_{g Y}$ & 0.008 & 0.008 & 0.0109 & 0.0109 \\
\hline$\sigma_{g C} / \sigma_{g Y}$ & 0.587 & 0.664 & 0.338 & 0.327 \\
\hline$\sigma_{g I_{K}} / \sigma_{g Y}$ & 2.59 & 1.712 & 3.504 & 3.442 \\
\hline$\sigma_{g l} / \sigma_{g Y}$ & 1.376 & 0.344 & 0.708 & 0.689 \\
\hline$\sigma_{g l} / \sigma_{g w}$ & 1.057 & 0.478 & 1.744 & 1.699 \\
\hline$\sigma_{g G} / \sigma_{g Y}$ & 1.496 & 1.934 & 1.432 & 1.438 \\
\hline$\rho(g C, g Y)$ & 0.595 & 0.949 & 0.515 & 0.582 \\
\hline$\rho\left(g I_{K}, g Y\right)$ & 0.743 & 0.957 & 0.931 & 0.934 \\
\hline$\rho(g l, g Y)$ & 0.436 & 0.870 & 0.943 & 0.950 \\
\hline$\rho(g l, g w)$ & -0.722 & 0.731 & 0.580 & 0.642 \\
\hline$\rho_{1}(g Y)$ & 0.381 & 0.0069 & -0.223 & -0.007 \\
\hline$\rho_{1}(g C)$ & 0.279 & 0.0347 & 0.498 & 0.015 \\
\hline \hline & & & & \\
\hline \hline HP-Filtered & U.S. & Unanticipated & 1 -quarter & 3 -quarter \\
\hline Data & Data & Benchmark & Anticipated & Anticipated \\
\hline$\sigma_{Y}$ & 0.0144 & 0.0103 & 0.0114 & 0.0128 \\
\hline$\sigma_{C} / \sigma_{Y}$ & 0.545 & 0.666 & 0.526 & 0.364 \\
\hline$\sigma_{I_{K}} / \sigma_{Y}$ & 2.64 & 1.707 & 2.638 & 3.213 \\
\hline$\sigma_{l} / \sigma_{Y}$ & 1.034 & 0.345 & 0.531 & 0.644 \\
\hline$\sigma_{l} / \sigma_{w}$ & 1.401 & 0.478 & 0.903 & 1.445 \\
\hline$\sigma_{G} / \sigma_{Y}$ & 1.178 & 1.941 & 1.745 & 1.553 \\
\hline$\rho(C, Y)$ & 0.859 & 0.947 & 0.803 & 0.684 \\
\hline$\rho\left(I_{K}, Y\right)$ & 0.910 & 0.956 & 0.895 & 0.925 \\
\hline$\rho(l, Y)$ & 0.737 & 0.866 & 0.880 & 0.943 \\
\hline$\rho(l, w)$ & -0.402 & 0.722 & 0.592 & 0.669 \\
\hline & & & & \\
\hline & & & & \\
\hline & & & & \\
\hline & & & & \\
\hline
\end{tabular}

Notation: $\sigma_{x}$ gives the standard deviation of variable $x . \quad \rho(x, y)$ gives the correlation of variables $x$ and $y . \rho_{1}(x)$ gives the first-order autocorrelation of variable $x . g x$ denotes the growth rate of variable $x$. $Y$ denotes output, $C$ consumption, $I_{K}$ capital investment, $l$ total hours, $G$ government expenditure, and $w$ average labour productivity which we calculate as $Y / l$. 


\section{Conclusion}

This paper points out that negative comovements between macroeconomic aggregates are common in US data and that this is not explained by conventional business cycle models which emphasize positive comovements only. As in Cogley and Nason (1995) we find that HP-filtering can severely mask the true underlying relationships in the data, in this case leading to a spurious predominance of positive comovements.

Finding relatively little evidence against it, we argue that observed negative comovements can be readily explained in simple Neoclassical models by "anticipation effects"; the dynamic responses to signals (news) about future economic fundamentals unrelated to current fundamentals. These "anticipation effects" are contrasted with the effects of immediate shocks to current fundamentals which are the main source of fluctuations in standard RBC models.

Simulation results illustrate that the enriched model dynamics under the anticipation assumption can replicate both the positive and negative comovements observed in the data. In addition, anticipation magnifies the effects of shocks without appealing to particular structural features of the model, and without negative implications for the model's predictions regarding other moments.

This paper is not arguing that the anticipation assumption is a fix for all of the failures of Neoclassical $\mathrm{RBC}$ models. The point is that anticipation effects in this model provide a ready explanation for a significant fraction of the observed comovements that are not explained under the standard alternative and thus, ceteris paribus, they represent an improvement in the overall modeling approach. While it is clearly possible to deliver negative comovements with the introduction of multiple shocks affecting only current fundamentals, anticipation effects are relatively simple. Furthermore, because the basic mechanism at work here - the optimal separation of wealth and substitution effects over time - is inherent to any intertemporal optimization framework, it stands to reason that similar improvements will be available in more sophisticated models. These effects warrant further study by macroeconomists. 


\section{References}

[1] Baxter, M., King, R., 1991. "Productive externalities and business cycles". Discussion paper \#53, Federal Reserve Bank of Minneapolis.

[2] Beaudry, Paul, and Franck Portier, (2003), "Stock Prices, News and Economic Fluctuations", NBER Working Paper \#10548.

[3] Beaudry, Paul, and Franck Portier, (2004a), "An Exploration into Pigou's Theory of Cycles", Journal of Monetary Economics, 51(6), 1183-1216.

[4] Beaudry, Paul, and Franck Portier, (2004b), "When can Changes in Expectations Cause Business Cycle Fluctuations in Neo-Classical Settings?", NBER Working Paper \#10776.

[5] Blanchard, Olivier Jean, and Danny Quah, "The Dynamic Effects of Aggregate Demand and Supply Disturbances", American Economic Review, Vol. 79, Number 4, (Sept. 1989): 655-673.

[6] Canova, Fabio, "Detrending and Business Cycle Facts", Journal of Monetary Economics, 41, (1998), 475-512.

[7] Cogley, Timothy, and James M. Nason, "Impulse Dynamics and Propagation Mechanisms in a Real Business Cycle Model", Economics Letters, December 1993, 43(4), pp. 77-81.

[8] Cogley, Timothy, and James M. Nason, "Output Dynamics in Real-Business-Cycle Models", American Economic Review, Vol. 85, Number 3, (June 1995): 492-511.

[9] Cogley, Timothy, and James M. Nason (1995), "Effects of the Hodrick-Prescott Filter on Trend and Difference Stationary Time Series. Implications for Business Cycle Research" Journal of Economic Dynamics and Control, 19, 253-278.

[10] Christiano, Lawrence J. and Martin Eichenbaum, "Current Real-Business-Cycle Theories and Aggregate Labor-Market Fluctuations", American Economic Review, June 1992, 82(3), pp. 430-50.

[11] Fair, R. C., and Taylor J.B., "Solution and Maximum Likelihood Estimation of Dynamic Nonlinear Rational Expectations Models", Econometrica, 51, (1983): 1169-1185.

[12] Gagnon, Joseph E., "Solving the Stochastic Growth Model by Deterministic Extended Path", Journal of Business \& Economic Statistics", Vol. 8, No. 1, (January 1990).

[13] Gomme, P., "Money and Growth Revisited, Measuring the Costs of Inflation in an Endogenous Growth Model", Journal of Monetary Economics, 32 (1993) 51-77. 
[14] Greenwood, Jeremy, Zvi Hercowitz and Per Krusell, "The Role of Investment-specific Technological Change in the Business Cycle", European Economic Review, 44, (2000), 91-115.

[15] Ingram, B.E., Narayana R. Kocherlakota, and N.E. Savin, "Explaining Business Cycles, A MultipleShock Approach", Journal of Monetary Economics, 34 (1994) 415-428.

[16] Jaimovich, Nir, and Sergio Rebelo, (2006) "Can News About the Future Drive the Business Cycle?", NBER Working Paper \#12537.

[17] Judd, Kenneth L., "Projection Methods for Solving Aggregate Growth Models", Journal of Economic Theory, 58, (1992) 410-452

[18] Love, D.R.F., and J.F. Lamarche (2004) "Anticipation and Real Business Cycles", Brock University Working Paper, http://spartan.ac.brocku.ca/ loved/papers/Ant-v3.

[19] Love, D.R.F., (2007) "Accuracy of Extended Path Method for Solving Aggregate Growth Models", Brock University Working paper, http://spartan.ac.brocku.ca/ loved/papers/Accuracy.

[20] Mehra, R. and E.C. Prescott, "The equity premium: A puzzle", Journal of Monetary Economics, 22 (1985), 3-42.

[21] Prescott, Edward C. "Theory Ahead of Business Cycle Measurement" Carnegie-Rochester Conference Series on Public Policy, 25, (Autumn 1986): 11-44.

[22] Rebelo, S.T. "Long-run Policy Analysis and Long-run Growth", Journal of Political Economy, 99, (1991): $500-21$.

[23] Taylor, J.B., and Uhlig, H., "Solving Nonlinear Stochastic Growth Models: A Comparison of Alternative Solution Methods", Journal of Business and Economic Statistics, 8, (1990): 1-17. 


\section{Appendix A: Data.}

The data series employed are, seasonally adjusted, real per-capita, quarterly figures for the U.S. economy covering the period 1953:1 to 2006:2. Real seasonally adjusted values where obtained and compiled from the Federal Reserve Economic Database (FRED) as follows. Real consumption was constructed as the sum of real personal consumption expenditures on non-durables (PCNDC96) and services (PCESVC96). Real capital investment was constructed as the sum of real private fixed investment (FPIC96), federal defense investment (DGIC96), federal non-defense investment (NDGIC96), state and local investment (SLINVC96), and private consumption expenditures on durables (PCDGC96). Real government expenditure was constructed as real government consumption plus gross investment (GCEC96) less the sum of federal defense investment, federal non-defense investment, and state and local investment. Real output was then constructed as the sum of real consumption, real capital investment, real government expenditure as defined above, plus the change in real private inventories (CBI96). Each of these constructed series was converted into per-capita terms by dividing by the civilian population 16 years of age and older (CNP16OV).

Our measure of "hours worked" accords closely with the Citibase "Lhours" series which was not used as it ends at the last month of 1993 . Thus we constructed;

$$
\begin{aligned}
\text { hours } & =\text { avg.hrs. } \times \text { employment rate } \times \text { participation rate } \\
& =\text { avg.hrs. } \times \text { employment } \div \text { population }
\end{aligned}
$$

where avg.hrs. was given by, the NBER series "average hours of work per week, nonagricultural employment" (M08304) for the period 1953:1 to 1963:3 and, because this series runs only until the end of the 1960's, we employed the comparable BLS series "average weekly hours, total private industries" (AWHNONAG) for the rest of the sample. As these series are monthly they had to be aggregated to quarterly values. As they represent "weekly" hours we then multiplied by 13 to obtain "quarterly" hours. To convert to a "per worker" basis, as indicated above, we multiplied by civilian employment 16 years and older (CE16OV) divided by CNP16OV. These figures where then converted to percentage terms by dividing by 1456 hours, which assumes a normalization of the unit of time available for work of 16 hours per day, 7 days per week, 13 weeks per quarter. Finally, the early part of the sample formed from the NBER data was divided by 1.0482 in order to scale it to be consistent with the later part of the sample based on the BLS series. This scaling factor is simply the average of the difference between the two series for that part of the sample for which they overlap (i.e. $1963: 3$ to $1969: 4)$. 


\section{Appendix B: Business Cycle Dates and Comovements.}

Table 11: NBER Business Cycle Dates and Comovements

\begin{tabular}{|c|c|c|c|c|}
\hline Date & $(1-L) x_{t}-\bar{\mu}$ & $H P_{t}$ & $(1-L)^{2} x_{t}$ & $(1-L) H P_{t}$ \\
\hline 1953:1 & IV & IV & NA & IV \\
\hline NBER Peak & I & IV & $\mathrm{I}$ & $\mathrm{I}$ \\
\hline $1953: 3$ & I & IV & I & I \\
\hline 1953:4 & III & I & IV & I \\
\hline 1954:1 & III & I & IV & IV \\
\hline NBER Trough & III & I & III & IV \\
\hline $1954: 3$ & IV & $\mathrm{I}$ & II & IV \\
\hline $1957: 1$ & I & IV & III & I \\
\hline $1957: 2$ & III & IV & IV & IV \\
\hline NBER Peak & I & IV & I & I \\
\hline 1957:4 & I & III & $\mathrm{I}$ & $\mathrm{I}$ \\
\hline 1958:1 & III & I & IV & III \\
\hline NBER Trough & IV & I & IV & IV \\
\hline 1958:3 & II & $\mathrm{I}$ & II & II \\
\hline 1959:4 & II & IV & II & II \\
\hline 1960:1 & III & IV & III & III \\
\hline NBER Peak & I & IV & II & I \\
\hline $1960: 3$ & I & I & III & I \\
\hline 1960:4 & III & I & IV & I \\
\hline NBER Trough & III & I & III & III \\
\hline 1961:2 & II & $\mathrm{I}$ & II & II \\
\hline 1969:2 & $\mathrm{I}$ & IV & II & II \\
\hline $1969: 3$ & III & IV & III & III \\
\hline NBER Peak & I & III & II & III \\
\hline $1970: 1$ & $\mathrm{I}$ & III & $\mathrm{I}$ & $\mathrm{I}$ \\
\hline $1970: 2$ & II & I & IV & IV \\
\hline $1970: 3$ & I & I & I & I \\
\hline NBER Trough & II & I & II & II \\
\hline 1971:1 & II & I & II & IV \\
\hline
\end{tabular}


Table 13: NBER Business Cycle Dates and Comovements Con't.

\begin{tabular}{|c|c|c|c|c|}
\hline Date & $(1-L) x_{t}-\bar{\mu}$ & $H P_{t}$ & $(1-L)^{2} x_{t}$ & $(1-L) H P_{t}$ \\
\hline $1973: 2$ & $\mathrm{I}$ & IV & III & I \\
\hline $1973: 3$ & I & IV & I & I \\
\hline NBER Peak & I & IV & I & I \\
\hline 1974:1 & I & II & IV & I \\
\hline $1974: 2$ & I & II & I & I \\
\hline $1974: 3$ & I & II & I & I \\
\hline 1974:4 & I & $\mathrm{I}$ & IV & I \\
\hline NBER Trough & III & I & IV & III \\
\hline $1975: 2$ & II & $\mathrm{I}$ & II & II \\
\hline $1979: 3$ & $\mathrm{I}$ & IV & III & $\mathrm{I}$ \\
\hline 1979:4 & I & IV & II & I \\
\hline NBER Peak & I & IV & I & I \\
\hline $1980: 2$ & $\mathrm{I}$ & $\mathrm{I}$ & IV & IV \\
\hline NBER Trough & IV & I & IV & IV \\
\hline $1980: 4$ & II & III & I & II \\
\hline 1981:1 & I & II & III & III \\
\hline 1981:2 & I & I & II & $\mathrm{I}$ \\
\hline NBER Peak & $\bar{I}$ & $\bar{I}$ & III & $\bar{I}$ \\
\hline 1981:4 & I & I & IV & I \\
\hline 1982:1 & I & I & III & I \\
\hline $1982: 2$ & III & $\mathrm{I}$ & III & III \\
\hline $1982: 3$ & IV & $\mathrm{I}$ & IV & IV \\
\hline NBER Trough & IV & $\mathrm{I}$ & $\mathrm{I}$ & IV \\
\hline $1983: 1$ & IV & I & IV & IV \\
\hline $1990: 1$ & III & IV & III & III \\
\hline $1990: 2$ & I & IV & II & III \\
\hline NBER Peak & I & IV & $\mathrm{I}$ & $\mathrm{I}$ \\
\hline 1990:4 & I & I & III & I \\
\hline NBER Trough & III & I & IV & IV \\
\hline 1991:2 & $\mathrm{I}$ & $\mathrm{I}$ & II & II \\
\hline $2000: 3$ & III & IV & III & III \\
\hline $2000: 4$ & I & IV & II & I \\
\hline NBER Peak & I & IV & III & I \\
\hline $2001: 2$ & $\mathrm{I}$ & IV & III & $\mathrm{I}$ \\
\hline $2001: 3$ & II & III & IV & IV \\
\hline NBER Trough & $\mathrm{I}$ & III & $\mathrm{I}$ & $\mathrm{I}$ \\
\hline $2002: 1$ & I & III & II & I \\
\hline
\end{tabular}




\section{Appendix C: Frequency Tables, Alternative Specifications.}

\begin{tabular}{|c|}
\hline Model Parameters, Indivisible-Labour Calibration \\
\hline$A=1.0, \alpha=0.344, \delta=0.021$ \\
\hline$\beta=0.9926, \gamma=0.0037, I E S=1.0$ \\
\hline$\mu=0.0026, \sigma_{S}=0.0106, g=0.177, \rho=0.96, \sigma_{G}=0.019$ \\
\hline Balanced-Growth Variable Values \\
\hline$g=0.004, l=0.23, \sigma_{g_{Y}}=0.008$ \\
\hline$G / Y=0.177$, Kinv $/ Y=0.265, r-\delta=0.0114$ \\
\hline
\end{tabular}

Table 14: Indivisible Labour Model, Unanticipated Changes.

\begin{tabular}{|c|c|c|c|c|c|}
\hline \multicolumn{3}{|c|}{$(1-L)^{2} x_{t}$} & \multicolumn{3}{|c|}{$(1-L) H P_{t}$} \\
\hline \multicolumn{3}{|c|}{$\overline{C C^{-}}$} & \multirow{9}{*}{$\begin{array}{l}I_{K}^{-} Y^{-} H^{-} \\
I_{K}^{-} Y^{-} H^{+} \\
I_{K}^{-} Y^{+} H^{-} \\
I_{K}^{-} Y^{+} H^{+} \\
I_{K}^{+} Y^{-} H^{-} \\
I_{K}^{+} Y^{-} H^{+} \\
I_{K}^{+} Y^{+} H^{-} \\
I_{K}^{+} Y^{+} H^{+}\end{array}$} & \multicolumn{2}{|l|}{$\overline{C^{-}}$} \\
\hline \multirow{8}{*}{$\begin{array}{c}I_{K}^{-} Y^{-} H^{-} \\
I_{K}^{-} Y^{-} H^{+} \\
I_{K}^{-} Y^{+} H^{-} \\
I_{K}^{-} Y^{+} H^{+} \\
I_{K}^{+} Y^{-} H^{-} \\
I_{K}^{+} Y^{-} H^{+} \\
I_{K}^{+} Y^{+} H^{-} \\
I_{K}^{+} Y^{+} H^{+}\end{array}$} & $31.1 \%$ & $3.9 \%$ & & $31.1 \%$ & $4.0 \%$ \\
\hline & $12.5 \%$ & $0 \%$ & & $12.5 \%$ & $0 \%$ \\
\hline & $0 \%$ & $0 \%$ & & $0 \%$ & $0 \%$ \\
\hline & $2.5 \%$ & $0 \%$ & & $2.4 \%$ & $0 \%$ \\
\hline & $0 \%$ & $2.4 \%$ & & $0 \%$ & $2.4 \%$ \\
\hline & $0 \%$ & $0 \%$ & & $0 \%$ & $0 \%$ \\
\hline & $0 \%$ & $12.4 \%$ & & $0 \%$ & $12.5 \%$ \\
\hline & $3.9 \%$ & $31.2 \%$ & & $4.0 \%$ & $31.1 \%$ \\
\hline
\end{tabular}

Table 15: Indivisible Labour Model, Anticipated Changes.

\begin{tabular}{|c|c|c|c|c|c|}
\hline \multicolumn{3}{|c|}{$(1-L)^{2} x_{t}$} & \multicolumn{3}{|c|}{$(1-L) H P_{t}$} \\
\hline \multirow{9}{*}{$\begin{array}{c}I_{K}^{-} Y^{-} H^{-} \\
I_{K}^{-} Y^{-} H^{+} \\
I_{K}^{-} Y^{+} H^{-} \\
I_{K}^{-} Y^{+} H^{+} \\
I_{K}^{+} Y^{-} H^{-} \\
I_{K}^{+} Y^{-} H^{+} \\
I_{K}^{+} Y^{+} H^{-} \\
I_{K}^{+} Y^{+} H^{+}\end{array}$} & $\overline{C^{-}}$ & $\overline{C^{+}}$ & \multirow{9}{*}{$\begin{array}{l}I_{K}^{-} Y^{-} H^{-} \\
I_{K}^{-} Y^{-} H^{+} \\
I_{K}^{-} Y^{+} H^{-} \\
I_{K}^{-} Y^{+} H^{+} \\
I_{K}^{+} Y^{-} H^{-} \\
I_{K}^{+} Y^{-} H^{+} \\
I_{K}^{+} Y^{+} H^{-} \\
I_{K}^{+} Y^{+} H^{+}\end{array}$} & \multicolumn{2}{|l|}{$C^{-}$} \\
\hline & $20.5 \%$ & $25.6 \%$ & & $19.4 \%$ & $26.5 \%$ \\
\hline & $1.0 \%$ & $0 \%$ & & $0.9 \%$ & $0 \%$ \\
\hline & $0 \%$ & $2.0 \%$ & & $0 \%$ & $1.9 \%$ \\
\hline & $0.6 \%$ & $1.0 \%$ & & $0.4 \%$ & $0.9 \%$ \\
\hline & $0.8 \%$ & $0.4 \%$ & & $0.8 \%$ & $0.4 \%$ \\
\hline & $1.8 \%$ & $0 \%$ & & $2.0 \%$ & $0 \%$ \\
\hline & $0 \%$ & $0.8 \%$ & & $0 \%$ & $0.9 \%$ \\
\hline & $25.4 \%$ & $20.1 \%$ & & $26.5 \%$ & $19.3 \%$ \\
\hline
\end{tabular}


Frequency Tables, Alternative Specifications Cont'd

\begin{tabular}{|c|}
\hline Model Parameters, Low-IES Calibration. \\
\hline$A=1.0, \alpha=0.35, \delta=0.024$ \\
\hline$\beta=0.987, \varepsilon=0.1783, \sigma=4.0, I E S=0.6515$ \\
\hline$\mu=0.0027, \sigma_{S}=0.0066, g=0.177, \rho=0.96, \sigma_{G}=0.0118$ \\
\hline Balanced-Growth Variable Values \\
\hline$g=0.0042, l=0.191, \sigma_{g_{Y}}=0.008$ \\
\hline$G / Y=0.177, \operatorname{Kinv} / Y=0.226, r-\delta=0.0197$ \\
\hline
\end{tabular}

Table 16: Low IES=0.6515, Unanticipated Changes.

\begin{tabular}{|c|c|c|c|c|c|}
\hline \multicolumn{3}{|c|}{$(1-L)^{2} x_{t}$} & \multicolumn{3}{|c|}{$(1-L) H P_{t}$} \\
\hline \multirow{9}{*}{$\begin{array}{c}I_{K}^{-} Y^{-} H^{-} \\
I_{K}^{-} Y^{-} H^{+} \\
I_{K}^{-} Y^{+} H^{-} \\
I_{K}^{-} Y^{+} H^{+} \\
I_{K}^{+} Y^{-} H^{-} \\
I_{K}^{+} Y^{-} H^{+} \\
I_{K}^{+} Y^{+} H^{-} \\
I_{K}^{+} Y^{+} H^{+}\end{array}$} & $\overline{\overline{C C^{-}}}$ & $\overline{C^{+}}$ & \multirow{9}{*}{$\begin{array}{c}I_{K}^{-} Y^{-} H^{-} \\
I_{K}^{-} Y^{-} H^{+} \\
I_{K}^{-} Y^{+} H^{-} \\
I_{K}^{-} Y^{+} H^{+} \\
I_{K}^{+} Y^{-} H^{-} \\
I_{K}^{+} Y^{-} H^{+} \\
I_{K}^{+} Y^{+} H^{-} \\
I_{K}^{+} Y^{+} H^{+}\end{array}$} & \multicolumn{2}{|l|}{$\overline{C^{-}}$} \\
\hline & $37.1 \%$ & $0.5 \%$ & & $36.9 \%$ & $0.8 \%$ \\
\hline & $7.9 \%$ & $0 \%$ & & $7.8 \%$ & $0 \%$ \\
\hline & $0 \%$ & $0 \%$ & & $0 \%$ & $0 \%$ \\
\hline & $4.4 \%$ & $0 \%$ & & $4.2 \%$ & $0 \%$ \\
\hline & $0 \%$ & $4.5 \%$ & & $0 \%$ & $4.3 \%$ \\
\hline & $0 \%$ & $0 \%$ & & $0 \%$ & $0 \%$ \\
\hline & $0 \%$ & $7.8 \%$ & & $0 \%$ & $7.8 \%$ \\
\hline & $0.5 \%$ & $37.1 \%$ & & $0.7 \%$ & $36.8 \%$ \\
\hline
\end{tabular}

Table 17: Low IES=0.6515, Anticipated Changes.

\begin{tabular}{|c|c|c|c|c|c|}
\hline \multicolumn{3}{|c|}{$(1-L)^{2} x_{t}$} & \multicolumn{3}{|c|}{$(1-L) H P_{t}$} \\
\hline \multirow{9}{*}{$\begin{array}{c}I_{K}^{-} Y^{-} H^{-} \\
I_{K}^{-} Y^{-} H^{+} \\
I_{K}^{-} Y^{+} H^{-} \\
I_{K}^{-} Y^{+} H^{+} \\
I_{K}^{+} Y^{-} H^{-} \\
I_{K}^{+} Y^{-} H^{+} \\
I_{K}^{+} Y^{+} H^{-} \\
I_{K}^{+} Y^{+} H^{+}\end{array}$} & $C^{-}$ & $C^{+}$ & \multirow{9}{*}{$\begin{array}{l}I_{K}^{-} Y^{-} H^{-} \\
I_{K}^{-} Y^{-} H^{+} \\
I_{K}^{-} Y^{+} H^{-} \\
I_{K}^{-} Y^{+} H^{+} \\
I_{K}^{+} Y^{-} H^{-} \\
I_{K}^{+} Y^{-} H^{+} \\
I_{K}^{+} Y^{+} H^{-} \\
I_{K}^{+} Y^{+} H^{+}\end{array}$} & \multicolumn{2}{|l|}{$\overline{C^{-}}$} \\
\hline & $28.0 \%$ & $14.3 \%$ & & $28.2 \%$ & $14.7 \%$ \\
\hline & $1.6 \%$ & $0 \%$ & & $1.5 \%$ & $0 \%$ \\
\hline & $0 \%$ & $3.2 \%$ & & $0 \%$ & $3.2 \%$ \\
\hline & $0.7 \%$ & $1.7 \%$ & & $0.7 \%$ & $1.7 \%$ \\
\hline & $1.8 \%$ & $0.7 \%$ & & $1.7 \%$ & $0.7 \%$ \\
\hline & $3.4 \%$ & $0 \%$ & & $3.1 \%$ & $0 \%$ \\
\hline & $0 \%$ & $1.7 \%$ & & $0 \%$ & $1.5 \%$ \\
\hline & $14.4 \%$ & $28.4 \%$ & & $14.8 \%$ & $28.2 \%$ \\
\hline
\end{tabular}


Frequency Tables, Alternative Specifications Cont'd

\begin{tabular}{|c|}
\hline Model Parameters, High-IES Calibration \\
\hline$A=1.0, \alpha=0.35, \delta=0.024$ \\
\hline$\beta=0.987, \varepsilon=0.1783, \sigma=0.1, I E S=0.191$ \\
\hline$\mu=0.0027, \sigma_{S}=0.004975, g=0.177, \rho=0.96, \sigma_{G}=0.0089$ \\
\hline Balanced-Growth Variable Values \\
\hline$g=0.0042, l=0.192, \sigma_{g_{Y}}=0.008$ \\
\hline$G / Y=0.177$, Kinv $/ Y=0.231, r-\delta=0.0167$ \\
\hline
\end{tabular}

Table 18: High IES=1.191, Unanticipated Changes.

\begin{tabular}{|c|c|c|c|c|c|}
\hline \multicolumn{3}{|c|}{$(1-L)^{2} x_{t}$} & \multicolumn{3}{|c|}{$(1-L) H P_{t}$} \\
\hline \multirow{9}{*}{$\begin{array}{c}I_{K}^{-} Y^{-} H^{-} \\
I_{K}^{-} Y^{-} H^{+} \\
I_{K}^{-} Y^{+} H^{-} \\
I_{K}^{-} Y^{+} H^{+} \\
I_{K}^{+} Y^{-} H^{-} \\
I_{K}^{+} Y^{-} H^{+} \\
I_{K}^{+} Y^{+} H^{-} \\
I_{K}^{+} Y^{+} H^{+}\end{array}$} & $C^{-}$ & $C^{+}$ & \multirow{9}{*}{$\begin{array}{l}I_{K}^{-} Y^{-} H^{-} \\
I_{K}^{-} Y^{-} H^{+} \\
I_{K}^{-} Y^{+} H^{-} \\
I_{K}^{-} Y^{+} H^{+} \\
I_{K}^{+} Y^{-} H^{-} \\
I_{K}^{+} Y^{-} H^{+} \\
I_{K}^{+} Y^{+} H^{-} \\
I_{K}^{+} Y^{+} H^{+}\end{array}$} & \multicolumn{2}{|l|}{$\overline{C^{-}}$} \\
\hline & $35.5 \%$ & $9.4 \%$ & & $34.9 \%$ & $9.7 \%$ \\
\hline & $3.7 \%$ & $0 \%$ & & $3.7 \%$ & $0 \%$ \\
\hline & $0 \%$ & $0 \%$ & & $0 \%$ & $0 \%$ \\
\hline & $1.5 \%$ & $0 \%$ & & $1.4 \%$ & $0 \%$ \\
\hline & $0 \%$ & $1.3 \%$ & & $0 \%$ & $1.4 \%$ \\
\hline & $0 \%$ & $0 \%$ & & $0 \%$ & $0 \%$ \\
\hline & $0 \%$ & $3.7 \%$ & & $0 \%$ & $3.6 \%$ \\
\hline & $9.2 \%$ & $35.5 \%$ & & $9.6 \%$ & $35 \%$ \\
\hline
\end{tabular}

Table 19: High IES=1.191, Anticipated Changes.

\begin{tabular}{|c|c|c|c|c|c|}
\hline \multicolumn{3}{|c|}{$(1-L)^{2} x_{t}$} & \multicolumn{3}{|c|}{$(1-L) H P_{t}$} \\
\hline \multirow{9}{*}{$\begin{array}{c}I_{K}^{-} Y^{-} H^{-} \\
I_{K}^{-} Y^{-} H^{+} \\
I_{K}^{-} Y^{+} H^{-} \\
I_{K}^{-} Y^{+} H^{+} \\
I_{K}^{+} Y^{-} H^{-} \\
I_{K}^{+} Y^{-} H^{+} \\
I_{K}^{+} Y^{+} H^{-} \\
I_{K}^{+} Y^{+} H^{+}\end{array}$} & $C^{-}$ & $\overline{C^{+}}$ & \multirow{9}{*}{$\begin{array}{c}I_{K}^{-} Y^{-} H^{-} \\
I_{K}^{-} Y^{-} H^{+} \\
I_{K}^{-} Y^{+} H^{-} \\
I_{K}^{-} Y^{+} H^{+} \\
I_{K}^{+} Y^{-} H^{-} \\
I_{K}^{+} Y^{-} H^{+} \\
I_{K}^{+} Y^{+} H^{-} \\
I_{K}^{+} Y^{+} H^{+}\end{array}$} & \multicolumn{2}{|l|}{$\overline{\bar{C} C^{-}}$} \\
\hline & $8.4 \%$ & $38.1 \%$ & & $7.6 \%$ & $38.8 \%$ \\
\hline & $0.9 \%$ & $0 \%$ & & $0.8 \%$ & $0 \%$ \\
\hline & $0 \%$ & $2.0 \%$ & & $0 \%$ & $1.7 \%$ \\
\hline & $0.5 \%$ & $0.8 \%$ & & $0.4 \%$ & $0.7 \%$ \\
\hline & $0.6 \%$ & $0.4 \%$ & & $0.7 \%$ & $0.4 \%$ \\
\hline & $1.8 \%$ & $0 \%$ & & $1.7 \%$ & $0 \%$ \\
\hline & $0 \%$ & $0.7 \%$ & & $0 \%$ & $0.7 \%$ \\
\hline & $37.9 \%$ & $8.0 \%$ & & $38.8 \%$ & $7.6 \%$ \\
\hline
\end{tabular}




\section{Appendix D: RBC Statistics, Alternative Specifications.}

Table 20: RBC Statistics: (Benchmark IES=1.0) Model

\begin{tabular}{|c|c|c|c|c|}
\hline $\begin{array}{c}(1-L) \text {-Filtered } \\
\text { Data }\end{array}$ & $\begin{array}{c}\text { U.S. } \\
\text { Data }\end{array}$ & $\begin{array}{c}\text { Unanticipated } \\
\text { Benchmark }\end{array}$ & $\begin{array}{c}\text { 1-quarter } \\
\text { Anticipated }\end{array}$ & $\begin{array}{c}\text { 3-quarter } \\
\text { Anticipated }\end{array}$ \\
\hline \hline$\sigma_{g Y}$ & 0.008 & 0.008 & 0.0116 & 0.0115 \\
\hline$\sigma_{g C} / \sigma_{g Y}$ & 0.587 & 0.474 & 0.287 & 0.262 \\
\hline$\sigma_{g I_{K}} / \sigma_{g Y}$ & 2.59 & 2.077 & 3.54 & 3.493 \\
\hline$\sigma_{g l} / \sigma_{g Y}$ & 1.376 & 0.471 & 0.842 & 0.825 \\
\hline$\sigma_{g l} / \sigma_{g w}$ & 1.057 & 0.811 & 2.972 & 2.942 \\
\hline$\sigma_{g G} / \sigma_{g Y}$ & 1.496 & 1.691 & 1.178 & 1.185 \\
\hline$\rho(g C, g Y)$ & 0.595 & 0.897 & -0.205 & -0.158 \\
\hline$\rho\left(g I_{K}, g Y\right)$ & 0.743 & 0.982 & 0.963 & 0.965 \\
\hline$\rho(g l, g Y)$ & 0.436 & 0.940 & 0.967 & 0.970 \\
\hline$\rho(g l, g w)$ & -0.722 & 0.809 & 0.437 & 0.516 \\
\hline$\rho_{1}(g Y)$ & 0.381 & 0.0026 & -0.254 & -0.009 \\
\hline$\rho_{1}(g C)$ & 0.279 & 0.079 & 0.110 & 0.031 \\
\hline \hline & & & & \\
\hline \hline HP-Filtered & U.S. & Unanticipated & 1 -quarter & 3 -quarter \\
\hline Data & Data & Benchmark & Anticipated & Anticipated \\
\hline$\sigma_{Y}$ & 0.0144 & 0.0103 & 0.0117 & 0.0135 \\
\hline$\sigma_{C} / \sigma_{Y}$ & 0.545 & 0.482 & 0.370 & 0.253 \\
\hline$\sigma_{I_{K}} / \sigma_{Y}$ & 2.64 & 2.067 & 2.838 & 3.297 \\
\hline$\sigma_{l} / \sigma_{Y}$ & 1.034 & 0.470 & 0.663 & 0.776 \\
\hline$\sigma_{l} / \sigma_{w}$ & 1.401 & 0.803 & 1.475 & 2.480 \\
\hline$\sigma_{G} / \sigma_{Y}$ & 1.178 & 1.697 & 1.481 & 1.288 \\
\hline$\rho(C, Y)$ & 0.859 & 0.891 & 0.529 & 0.090 \\
\hline$\rho\left(I_{K}, Y\right)$ & 0.910 & 0.980 & 0.945 & 0.962 \\
\hline$\rho(l, Y)$ & 0.737 & 0.934 & 0.932 & 0.969 \\
\hline$\rho(l, w)$ & -0.402 & 0.792 & 0.595 & 0.613 \\
\hline & & & & \\
\hline & & & & \\
\hline & & & & \\
\hline & & & & \\
\hline
\end{tabular}

Notation: $\sigma_{x}$ gives the standard deviation of variable $x . \quad \rho(x, y)$ gives the correlation of variables $x$ and $y . \quad \rho_{1}(x)$ gives the first-order autocorrelation of variable $x . g x$ denotes the growth rate of variable $x . Y$ denotes output, $C$ consumption, $I_{K}$ capital investment, $l$ total hours, $G$ government expenditure, and $w$ average labour productivity which we calculate as $Y / l$. 
Table 21: RBC Statistics: Indivisible Labour (IES=1.0) Model

\begin{tabular}{|c|c|c|c|c|}
\hline $\begin{array}{c}(1-L) \text {-Filtered } \\
\text { Data }\end{array}$ & $\begin{array}{c}\text { U.S. } \\
\text { Data }\end{array}$ & $\begin{array}{c}\text { Unanticipated } \\
\text { Benchmark }\end{array}$ & $\begin{array}{c}\text { 1-quarter } \\
\text { Anticipated }\end{array}$ & $\begin{array}{c}\text { 3-quarter } \\
\text { Anticipated }\end{array}$ \\
\hline \hline$\sigma_{g Y}$ & 0.008 & 0.008 & 0.0197 & 0.0187 \\
\hline$\sigma_{g C} / \sigma_{g Y}$ & 0.587 & 0.766 & 0.257 & 0.198 \\
\hline$\sigma_{g I_{K}} / \sigma_{g Y}$ & 2.59 & 1.258 & 4.008 & 3.824 \\
\hline$\sigma_{g l} / \sigma_{g Y}$ & 1.376 & 0.419 & 1.099 & 1.033 \\
\hline$\sigma_{g l} / \sigma_{g w}$ & 1.057 & 0.548 & 4.279 & 5.231 \\
\hline$\sigma_{g G} / \sigma_{g Y}$ & 1.496 & 1.957 & 0.848 & 0.893 \\
\hline$\rho(g C, g Y)$ & 0.595 & 0.921 & -0.277 & -0.073 \\
\hline$\rho\left(g I_{K}, g Y\right)$ & 0.743 & 0.988 & 0.973 & 0.976 \\
\hline$\rho(g l, g Y)$ & 0.436 & 0.702 & 0.974 & 0.982 \\
\hline$\rho(g l, g w)$ & -0.722 & 0.371 & -0.486 & -0.262 \\
\hline$\rho_{1}(g Y)$ & 0.381 & 0.0041 & -0.404 & -0.044 \\
\hline$\rho_{1}(g C)$ & 0.279 & 0.0122 & 0.213 & 0.129 \\
\hline \hline & & & & \\
\hline \hline HP-Filtered & U.S. & Unanticipated & 1 -quarter & 3 -quarter \\
\hline Data & Data & Benchmark & Anticipated & Anticipated \\
\hline$\sigma_{Y}$ & 0.0144 & 0.0109 & 0.0162 & 0.0202 \\
\hline$\sigma_{C} / \sigma_{Y}$ & 0.545 & 0.765 & 0.449 & 0.268 \\
\hline$\sigma_{I_{K}} / \sigma_{Y}$ & 2.64 & 1.257 & 3.409 & 3.729 \\
\hline$\sigma_{l} / \sigma_{Y}$ & 1.034 & 0.421 & 0.944 & 1.015 \\
\hline$\sigma_{l} / \sigma_{w}$ & 1.401 & 0.553 & 2.115 & 3.819 \\
\hline$\sigma_{G} / \sigma_{Y}$ & 1.178 & 1.965 & 1.312 & 1.050 \\
\hline$\rho(C, Y)$ & 0.859 & 0.920 & 0.342 & 0.073 \\
\hline$\rho\left(I_{K}, Y\right)$ & 0.910 & 0.988 & 0.910 & 0.960 \\
\hline$\rho(l, Y)$ & 0.737 & 0.703 & 0.895 & 0.965 \\
\hline$\rho(l, w)$ & -0.402 & 0.372 & -0.111 & -0.191 \\
\hline & & & & \\
\hline & & & & \\
\hline & & & & \\
\hline
\end{tabular}

Notation: $\sigma_{x}$ gives the standard deviation of variable $x . \quad \rho(x, y)$ gives the correlation of variables $x$ and $y . \quad \rho_{1}(x)$ gives the first-order autocorrelation of variable $x . g x$ denotes the growth rate of variable $x . Y$ denotes output, $C$ consumption, $I_{K}$ capital investment, $l$ total hours, $G$ government expenditure, and $w$ average labour productivity which we calculate as $Y / l$. 